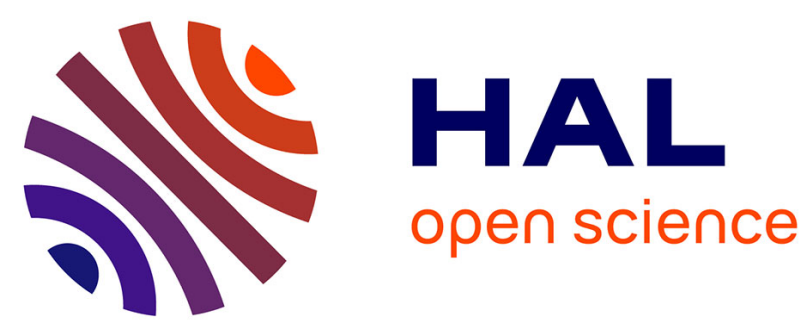

\title{
Bulge test and AFM point deflection method, two technics for the mechanical characterisation of very low stiffness freestanding films
}

P. Martins, P. Delobelle, C. Malhaire, S. Brida, Damien Barbier

\section{- To cite this version:}

P. Martins, P. Delobelle, C. Malhaire, S. Brida, Damien Barbier. Bulge test and AFM point deflection method, two technics for the mechanical characterisation of very low stiffness freestanding films. European Physical Journal: Applied Physics, 2009, 45 (1), pp.10501. 10.1051/epjap:2008187 . hal00480182

\section{HAL Id: hal-00480182 \\ https://hal.science/hal-00480182}

Submitted on 3 May 2010

HAL is a multi-disciplinary open access archive for the deposit and dissemination of scientific research documents, whether they are published or not. The documents may come from teaching and research institutions in France or abroad, or from public or private research centers.
L'archive ouverte pluridisciplinaire $\mathbf{H A L}$, est destinée au dépôt et à la diffusion de documents scientifiques de niveau recherche, publiés ou non, émanant des établissements d'enseignement et de recherche français ou étrangers, des laboratoires publics ou privés. 


\title{
BULGE TEST AND AFM POINT DEFLECTION METHOD, TWO TECHNICS FOR THE MECHANICAL CHARACTERISATION OF VERY LOW STIFFNESS FREESTANDING FILMS.
}

\author{
P. Martins ${ }^{1}$, P. Delobelle ${ }^{2}$, C. Malhaire ${ }^{1}$, S. Brida ${ }^{3}$, D. Barbier ${ }^{1}$ \\ ${ }^{1}$ Université de Lyon, INSA-Lyon, INL, CNRS UMR 5270, Villeurbanne, F-69621, France. \\ ${ }^{2}$ FEMTO-ST, LMARC, CNRS UMR 6174, Besançon, F-25000, France. \\ (Tel : 33-3-81666013 ; E-mail: patrick.delobelle@univ-fcomte.fr) \\ ${ }^{3}$ AUXITROL SA, Esterline Sensors Group, F-18941, France.
}

PACS numbers: 81.07-b Nanoscale materials and Structures: Fabrication and

Characterization, 62.25-g Mechanical Properties of Nanoscale Systems, 68.37-PS Atomic

Force Microscopy.

Short Title: Mechanical Characterization of Low Stiffness Freestanding Dielectric Films

\begin{abstract}
The aim of this work is to compare several methods for the determination of very thin films Young's modulus and stress state: the nanoindentation test, the bulge test and the point-deflection method. The tested structures were silicon nitride and silicon nitride/silicon oxide bilayer membranes with different shapes (square or rectangular) and dimensions (from $1 \mathrm{~mm}$ to $3 \mathrm{~mm}$ ). We report new experimental results on submicron thick dielectric membranes with thicknesses down to $100 \mathrm{~nm}$. A Young's modulus of $217 \pm 14 \mathrm{GPa}$ have been found for silicon nitride membranes with a residual stress of $411 \pm 30 \mathrm{MPa}$ using the bulge test. Using nanoindentation experiments, a Young's modulus higher than $190 \mathrm{GPa}$ has been estimated. The bulge test is still valid for the studied high dimension to thickness ratio membranes and more appropriate to determine the Young's modulus. A mixture law was shown to be possibly applied for $\mathrm{Si}_{3} \mathrm{~N}_{4} / \mathrm{SiO}_{2}$ bilayer membranes for the Young's modulus and stress determination. The point deflection method is limited by the very low stiffness of these structures and only the residual stress can be accurately extracted. As the Young's modulus and membrane geometry have no significant influence on the stress determination by means of the point deflection method for the studied membranes (with a high lateral dimension to thickness ratio), more reliable results have been obtained such as $487 \pm 40 \mathrm{MPa}$ using an AFM cantilever for load-deflection experiments, for $\mathrm{Si}_{3} \mathrm{~N}_{4}$ thin films.
\end{abstract}




\section{INTRODUCTION}

With the development of MicroElectroMechanical Systems (MEMS) and in a near future NanoElectroMechanical Systems (NEMS), the characterization of the mechanical properties of thin films becomes an important challenge. A precise knowledge of the Young's modulus, Poisson's ratio and stress state of thin film materials is critical for the development of simulation models and libraries for CAD softwares. The aim is to predict the mechanical behaviour of various free standing structures (membranes, cantilevers) to optimize their design and fabrication, and to improve device performances and reliability. For example, stress engineering becomes mandatory for the development of microphones or RF-MEMS. Indeed, a twisting of thin membranes can influence or even drastically degrade the device performances [1-3].

Moreover, mechanical characterization methods must be adapted to the thin submicron thick layers and complex multilayer encountered MEMS in architectures. It is far preferable that mechanical tests be carried out on thin films of the same thickness (understood, the same fabrication process) that those used in final devices. Indeed, parameters like grain size and preferential crystallographic orientation change along with the thickness and thus influence the mechanical properties in particular the stress gradient [4-8]. But the study of materials having a thickness less than one hundred nanometers becomes difficult. For example, nanoindentation does not apply for such films due to the substrate influence, pile-up or sink-in effects [9-12]. This will be shown in paragraph 4.1 for $100 \mathrm{~nm}$ thick $\mathrm{Si}_{3} \mathrm{~N}_{4}$ films.

All MEMS researchers have used the bending-plate method to determine the stress value of a thin film on a thick substrate through the use of a modified Stoney's equation [13]. However, silicon microtechnologies have offered the possibility to develop methods that allow the determination of several mechanical parameters at the same time; some are reported in [14-15]. For a long time, several methods have been developed to study the mechanical behaviour of self-standing thin film to determine their properties (no substrate effect and more straightforward mechanical parameters determination): bulge-test, Guckel rings, Euler columns...

In this study, the technics used to characterize our materials are the bulge test and the point deflection method. The bulge-test consists in pressurising a self-standing membrane (mono or multilayer) and measuring its maximum deflection. The more recent method, called pointdeflection method, consists in applying a point load at the membrane center (using a 
nanoindenter or an AFM). In both cases, analytical models allow the determination of the membrane's Young's modulus, stress state and the Poisson's ratio as well, under certain conditions.

The main objective of this study is to compare results obtained using both methods, and to derive experimental conditions for the characterization of very thin film materials. Insofar, as MEMS devices may be made up of multilayer, it was also interesting to check if the mixture law still applies for very thin films. Indeed, this very simple law is interesting to determine the mechanical properties of one component of the multilayer knowing others.

Even if the bulge-test method is well known, few papers report results obtained on $200 \mathrm{~nm}$ or less thin film materials or multilayers. Y. Xiang et al. [16] report results obtained on $\mathrm{SiN}_{\mathrm{x}}$ LPCVD/ $\operatorname{SiN}_{\mathrm{x}}$ PECVD rectangular $(2.4 \mathrm{~mm}$ x $10 \mathrm{~mm})$ bilayer membranes of about $100 \mathrm{~nm}$ only by the bulge test method without any comparison with another technique. M. K. Tripp et al. [17] have reported results on $100 \mathrm{~nm}$ thick $\mathrm{Al}_{2} \mathrm{O}_{3}$ circular membranes with a diameter of $200 \mu \mathrm{m}$ using different methods (bulge test, nanobeam deflection, nanoindentation and pointer rotation).

The point-deflection method seems promising for the study of very thin membranes [18-25] because very low point forces can be applied by means of an AFM tip. This has been shown by S. Markutsya et al. [26] for 25-70 $\mathrm{nm}$ thick polymer membranes. However, to our knowledge, no results are reported for very thin dielectric materials using an AFM tip.

In this paper, the mechanical properties (Young's modulus $\mathrm{E}$ and mean residual stress $\sigma_{0}$ ) of LPCVD $\mathrm{Si}_{3} \mathrm{~N}_{4}$ thin films (about $100 \mathrm{~nm}$ in thickness) and $\mathrm{Si}_{3} \mathrm{~N}_{4} / \mathrm{SiO}_{2}$ bilayers (about $200 \mathrm{~nm}$ in thickness) have been investigated. Membranes were realized with large lateral dimensions (between 1 and $3 \mathrm{~mm}$ ) in order to get width to thickness ratios greater than 5000 inducing very low stiffness and a high sensitivity to the external load. This last characteristic may be of interest for the realization of high sensitivity devices in various application fields (aerospace, biomedical, material separation, selective transport...) [1, 27-29].

\section{BACKGROUND}

\subsection{Nanoindentation}

These tests based on the Continuous Stiffness Method (CSM) have been performed in order to determine the Young's modulus of a $\mathrm{Si}_{3} \mathrm{~N}_{4}$ layer with a thickness t. According to W. C. Oliver and G. M. Pharr [30] the reduced Young's modulus $E_{r}$ is obtained from: 
$\mathrm{E}_{\mathrm{r}}=\frac{\sqrt{\pi}}{2 \delta \sqrt{\mathrm{A}}} \frac{\mathrm{dP}_{\mathrm{i}}}{\mathrm{dl}_{\mathrm{i}}}$

$\mathrm{P}_{\mathrm{i}}$ is the indentation load and $\mathrm{l}_{\mathrm{i}}$ the total indentation depth. $\mathrm{dP}_{\mathrm{i}} / \mathrm{dl}_{\mathrm{i}}=\mathrm{S}$ is the contact stiffness at depth $1_{\mathrm{i}}$. For a Berkovich indenter, $\delta=1.034$. The reduced Young's modulus $\mathrm{E}_{\mathrm{r}}$ is also given by:

$\frac{1}{\mathrm{E}_{\mathrm{r}}}=\frac{1-v^{2}}{\mathrm{E}}+\frac{1-v_{\mathrm{i}}^{2}}{\mathrm{E}_{\mathrm{i}}}$

$\mathrm{E}$ and $v$ are the elastic modulus and Poisson's ratio of the tested material, respectively, $\mathrm{E}_{\mathrm{i}}$ and $v_{i}$ are the same parameters for the diamond tip. A is the projected contact area expressed by:

$A=24,56 \cdot 1_{c}^{2}+\sum_{n=1}^{4}\left(a_{n} 1_{c}^{1 / n}\right)$

with

$1_{c}=1_{i}-\varepsilon \frac{P_{i}}{S}$

For a conic indenter $\varepsilon=0.72$. To avoid any influence of the substrate during indentation, it is necessary to limit indentation depth to thickness ratios $\left(\mathrm{l}_{\mathrm{i}} / \mathrm{t}\right)$ to $10 \%$ [9].

\subsection{Bulge test method}

The bulge test method consists in applying a pressure $\mathrm{P}$ on a membrane and in measuring the maximal deflection $h$ at its center (see Fig. 1). For the tested membranes, the deflections are very large, (h/t>>1) (Fig. 7 and 8) so, assuming a known Poisson's ratio for the material, both stress and Young's modulus can be determined from [31-36]:

$$
\frac{\mathrm{P}}{\mathrm{h}}=\mathrm{C}_{1}(\mathrm{a}, \mathrm{b}) \frac{\mathrm{t}}{\mathrm{a}^{2}} \sigma_{0}+\mathrm{f}(\mathrm{v}, \mathrm{a}, \mathrm{b}) \frac{\mathrm{t}}{\mathrm{a}^{4}} \frac{\mathrm{E}}{1-v} \mathrm{~h}^{2}
$$


Fig. 1 Bulge test principle.

$\mathrm{E}$ is the Young's modulus, $v$ the Poisson's ratio, $\mathrm{t}, 2 \mathrm{a}$ and $2 \mathrm{~b}$ stand for the membrane's thickness, width and length, respectively. Coefficients $C_{1}(a, b)$ and $f(v, a, b)$ are critical parameters in this study because they must be adjusted as a function of the membrane shape. Lot of studies have been made in order to optimize the associated analytical model [31-36]. It was assumed that in the case of square membranes $C_{1}=3.42$ and $f(v)=1.91(1-0.207 v)$ [35]. For rectangular membranes with an aspect ratio of 2 , coefficients $C_{1}$ and $f(v)$ have been recalculated using finite element simulations to give: $C_{1}=2.19$ and $f(v)=1.08(1-0.181 v)$ [35].

\subsection{Point deflection method}

Fig. 2: Point deflection method using a nanoindenter (on the left) or an AFM in spectrometry mode (on the right).

The third thin film characterization method, the so-called point-deflection method, has not been extensively used so far and can be applied to determine the average stress and biaxial modulus of free standing films $[18,26]$. It consists in determining the stiffness $\mathrm{S}_{0}$ of a membrane by applying a small concentrated transverse load $\mathrm{F}$ at its center by means of a nanoindenter or an AFM cantilever (see Fig. 2) and in measuring the corresponding out-ofplane displacement $\mathrm{h}$. The relationship between the applied load $\mathrm{F}$ and the maximal deflection $\mathrm{h}$ is given by [22]:

$$
\mathrm{F}=\frac{E \mathrm{t}^{3}}{12 \alpha\left(1-v^{2}\right) \mathrm{a}^{2} \mathrm{~g}\left(\mathrm{k}_{0}\right)} \mathrm{h}+\mathrm{C}\left(\mathrm{v}, \frac{\mathrm{h}}{\mathrm{t}}, \mathrm{k}_{0}\right) \frac{\mathrm{E} \mathrm{t}}{\mathrm{a}^{2}} \mathrm{~h}^{3}
$$

where " $\mathrm{a}$ " is the membrane's side and $\mathrm{g}\left(\mathrm{k}_{0}\right)$ stands for the unstressed and stressed membrane stiffness ratio. For unstressed membranes, $\mathrm{g}\left(\mathrm{k}_{0}\right)=1$

In the case of small deflections and for tensile residual stresses [22]: 


$$
\mathrm{C}=\frac{\mathrm{C}_{0}}{1-v^{2}}\left(1+\frac{\eta}{\mathrm{g}\left(\mathrm{k}_{0}\right)}\right)
$$

$$
\mathrm{k}_{0}^{2}=\frac{12\left(1-v^{2}\right)}{\beta^{2}}\left(\frac{\mathrm{a}}{\mathrm{t}}\right)^{2} \frac{\sigma_{0}}{\mathrm{E}}
$$

and

$$
\mathrm{g}\left(\mathrm{k}_{0}\right)=\frac{8}{\mathrm{k}_{0}^{2}}\left[\frac{\mathrm{K}_{1}\left(\mathrm{k}_{0}\right)-\frac{1}{\mathrm{k}_{0}}}{\mathrm{I}_{1}\left(\mathrm{k}_{0}\right)}\left(\mathrm{I}_{0}\left(\mathrm{k}_{0}\right)+1\right)+\mathrm{K}_{0}\left(\mathrm{k}_{0}\right)+\mathrm{Ln}\left(\frac{\mathrm{k}_{0}}{2}\right)+\gamma\right]=\frac{8}{\mathrm{k}_{0}^{2}} \mathrm{~g}^{\prime}\left(\mathrm{k}_{0}\right)
$$

$\mathrm{K}_{0}$ and $\mathrm{K}_{1}$ are the Bessel functions of the second kind of orders 0 and $1, \mathrm{I}_{0}$ and $\mathrm{I}_{1}$ are the modified Bessel functions of the first kind of order 0 and 1. The Euler's constant is noted $\gamma$ and the coefficient $\eta \approx 1.9 \times 10^{-2}$.

Combining Eqs. (6), (8) and (9), the residual stress $\sigma_{0}$ and the Young's modulus E can be extracted from:

$$
\mathrm{F}=\frac{\mathrm{t} \sigma_{0}}{8 \alpha \beta^{2} \mathrm{~g}^{\prime}\left(\mathrm{k}_{0}\right)} \mathrm{h}+\frac{\mathrm{C}_{0}}{1-\mathrm{v}^{2}}\left(1+\frac{\eta}{\mathrm{g}\left(\mathrm{k}_{0}\right)}\right) \frac{\mathrm{t} \mathrm{E}}{\mathrm{a}^{2}} \mathrm{~h}^{3}
$$

This method was developed for circular membranes. M. Józwik et al. [22] have determined the $\alpha, \beta$ and $\mathrm{C}_{0}$ values for rectangular (b/a=2 and 4) and square membranes (see Tab. 1) using finite element simulations $[18,22-23]$. Note that if $n=b / a, \beta$ is approximately equal to:

$$
\beta=\frac{0.93}{n} \sqrt{\frac{3 n^{4}+2 n^{2}+3}{1+n^{2}}} \text {, and thus for large values of } n, \beta \approx 1.61 \text {. This value agrees with }
$$
those determined using F.E. simulations: $\beta \approx 1.59$ (Tab.1)

Table 1: Values of the $\alpha, \beta$ and $C_{o}$ coefficients for different membrane shapes. 


\section{SAMPLES PREPARATION AND EXPERIMENTAL SETUP}

\subsection{Sample preparation}

Fig. 3: Membranes configurations.

Dielectric membranes have been fabricated on <100> p-type, double-side polished, $100 \mathrm{~mm}$ silicon substrates (noted Wafers 1, 2, 3 and 4 or W1, W2, W3, W4 in the different tables) using a standard micromachining process. Silicon nitride films $(100 \mathrm{~nm})$ have been deposited at $835^{\circ} \mathrm{C}$ by LPCVD on thermally oxidized $\left(100 \mathrm{~nm}\right.$ of $\left.\mathrm{SiO}_{2}\right)$ silicon substrates (Fig. 3). Free standing membranes have been obtained through silicon anisotropic etching in a $\mathrm{KOH}$ solution (Fig.3). Several samples (see Fig. 4) of the same shape have been realized (Tab. 2) with the aim to obtain a statistic approach of the overall result accuracy.

Table 2: Tested samples.

Fig. 4: Membranes after fabrication.

\subsection{Experimental setup}

During bulge-test experiments, the deflection h was measured as a function of the applied pressure P by means of a WYCO NT1100 white-light interferometer microscope (Fig. 5). Pressures ranging from 10 mbar up to 600 mbar, depending on the geometry, have been applied. The samples were fixed on a sample holder plate using wax instead of glue. Wax offered the advantage of being easily removed and soft during cool-down thus limiting membrane deformation effects (see section 4.4).

\section{Fig. 5: Optical Interferometer setup.}

Point deflection measurements have been first performed using a Nanoinstrument IIS Nanoindenter. However, the stiffness change of the indenter's head must be at least of 0.9 $\mathrm{N} . \mathrm{m}^{-1}$ to detect the contact with the membrane, which limits the applications to membranes with relatively high stiffness. The maximum deflection was fixed to $1.5 \mu \mathrm{m}$ to prevent membranes from breaking. More precise additional experiments have been carried out using a PSIA XE150 Atomic Force Microscope (AFM) in spectrometry mode (F/D forcedisplacement) where the spectrometry curve is a plot of the force F between the AFM tip and 
the sample versus the extension of the $\mathrm{Z}$ scanner (Figs. 10 and 11). In this case, the samples were only fixed on the $x-y$ positioning stage using a low strength adhesive tape. Thus, it was assumed that no additional stress was applied to the membranes.

For the nanoindentation tests, a total of 30 indentations have been performed on the membrane's frame to obtain representative values of the apparent Young's modulus.

\section{RESULTS AND DISCUSSION}

\subsection{Preliminary nanoindentation measurements}

Fig. 6 shows the evolution of the Young's modulus $\mathrm{E}$ as a function of $\mathrm{l}_{\mathrm{i}} / \mathrm{t}$ (where $\mathrm{t}$ and $\mathrm{l}_{\mathrm{i}}$ are the film thickness $(\sim 100 \mathrm{~nm})$ and nanoindenter penetration, respectively) for a $\mathrm{Si}_{3} \mathrm{~N}_{4} / \mathrm{SiO}_{2} /$ Si substrate sample.

Fig. 6: Determination of the Young's modulus by nanoindentation.

The Young's modulus of the film can be estimated by extrapolation of this curve to $1_{\mathrm{i}} / \mathrm{t}=0$ (see section 2.1). Assuming that $v=0.3$, this experiment allowed us to extract only a minimum Young's modulus value of $190 \mathrm{GPa}$. This inaccuracy on $\mathrm{E}$ is due to the fact that $\mathrm{t}$ is very small and results for $l_{i}<5 \mathrm{~nm}$ were not easy to exploit without the knowledge of the $E=f$ $\left(\mathrm{l}_{\mathrm{i}} / \mathrm{t}\right)$ function for very small $\mathrm{t}$ values [9] [11].

\subsection{Bulge test results}

Fig. 7 and 8 show the linearized representations $\mathrm{P} / \mathrm{h}$ as a function of $\mathrm{h}^{2}$ for the monolayer $\mathrm{Si}_{3} \mathrm{~N}_{4}$ and the bilayer $\mathrm{Si}_{3} \mathrm{~N}_{4} / \mathrm{SiO}_{2}$ membranes respectively. According to Eq. 5, the residual stress and the Young's modulus are calculated from the y-intercept coefficient and the slope of the curves, respectively. The measurement repeatability was better than $1 \%$ from one sample to another whatever the membrane geometries. Moreover, no hysteresis phenomena have been observed during load/unload cycles. This indicated a pure elastic behavior of the membranes even after repetitive large deflections.

Fig. 7: Normalized pressure-displacement $\left(P / h=f\left(h^{2}\right)\right)$ curves of $\mathrm{Si}_{3} \mathrm{~N}_{4}$ membranes.

Fig. 8: Normalized pressure-displacement $\left(\mathrm{P} / h=f\left(h^{2}\right)\right)$ curves of $\mathrm{Si}_{3} \mathrm{~N}_{4} / \mathrm{SiO}_{2}$ membranes.

Using a mixture law [37-38], the Poisson's ratio of the composite membrane can be calculated to determine the Young's modulus and the residual stress for a multilayer. 
$v_{c}=\Phi_{1} v_{1}+\Phi_{2} v_{2}+\ldots+\Phi_{n} v_{n}$

$v_{c}$ represents the Poisson's ratio of the composite material, $v_{1} \ldots v_{n}$ are the Poisson's ratio of each material and $\Phi_{1} \ldots \Phi_{\mathrm{n}}$ are the volume fraction of the constituent layers. For the composite $\mathrm{Si}_{3} \mathrm{~N}_{4} / \mathrm{SiO}_{2}$ membranes (W2, W4), a Poisson ratio value of 0.24 has been calculated using values of 0.3 [39] and 0.17 [40] for $\mathrm{Si}_{3} \mathrm{~N}_{4}$ and $\mathrm{SiO}_{2}$, respectively. The mechanical properties obtained for the different membrane shapes are summarized in Tables 6 and 7. For $\mathrm{Si}_{3} \mathrm{~N}_{4}$ membranes, the residual stress was $387<\sigma_{0}<439 \mathrm{MPa}$ and the Young's modulus was $209<$ $\mathrm{E}<231 \mathrm{GPa}$ on the wafers 1 and 3. The values obtained on the two wafers are close to each other. These results are in a fairly good agreement with literature values [41-43] for LPCVD silicon nitride films.

For the bilayer $\mathrm{Si}_{3} \mathrm{~N}_{4} / \mathrm{SiO}_{2}$ membranes (wafer 2), the composite values were $51<\sigma_{\text {composite }}$ $<54 \mathrm{MPa}$ and $155<\mathrm{E}_{\text {composite }}<159 \mathrm{GPa}$, and for the membranes of wafer 4, these values are $69<\sigma_{\text {composite }}<114 \mathrm{MPa}$ and $122<\mathrm{E}_{\text {composite }}<150 \mathrm{GPa}$. An attempt was made on the bilayer to extract the mechanical properties of the thermal silicon dioxide using the mixture law. Indeed, the Young's modulus and residual stress can be determined for each material component of the composite material using:

$\mathrm{M}_{\text {composite }}=\frac{\mathrm{t}_{\mathrm{Si}_{3} \mathrm{~N}_{4}}}{\mathrm{t}_{\text {total }}} \mathrm{M}_{\mathrm{Si}_{3} \mathrm{~N}_{4}}+\frac{\mathrm{t}_{\mathrm{SiO}_{2}}}{\mathrm{t}_{\text {total }}} \mathrm{M}_{\mathrm{SiO}_{2}}$

$\mathrm{M}$ represents either the residual stress or the biaxial modulus. With $\sigma_{\text {composite }} \approx 52.7 \mathrm{MPa}$ $(\mathrm{W} 2), \sigma_{\text {composite }} \approx 99 \mathrm{MPa}(\mathrm{W} 4)$ and $\sigma_{\mathrm{Si}_{3} \mathrm{~N}_{4}} \approx 411 \mathrm{MPa}$ (mean values), we obtained $\sigma_{\mathrm{SiO}_{2}} \approx-327$ $\mathrm{MPa}$ and $-187 \mathrm{MPa}$ for wafers 2 and 4 respectively. Assuming that $\mathrm{v}_{\mathrm{Si}_{3} \mathrm{~N}_{4}}=0.3, \mathrm{v}_{\mathrm{SiO}_{2}}=0.17$, $v_{\text {composite }}=0.24, \mathrm{ESi}_{3} \mathrm{~N}_{4}=217 \mathrm{GPa}$ and $\mathrm{E}_{\text {composite }}=157 \mathrm{GPa}$ for $\mathrm{W} 2$ and $\mathrm{E}_{\text {composite }}=141 \mathrm{GPa}$ for W4 (mean values), we found $\mathrm{ESiO}_{2}=94 \mathrm{GPa}$ and $71 \mathrm{GPa}$ respectively.

These values are in agreement with the literature for thermal silicon dioxide [22-23, 44] $\left(\mathrm{E}=72 \mathrm{GPa}\right.$ and $\left.-300<\sigma_{0}<-200 \mathrm{MPa}\right)$, especially for the wafer 4.

\subsection{Point deflection method}

\subsubsection{Nanoindenter method}


In Fig. 9, experimental $\mathrm{F}$ versus $\mathrm{h}$ curves are plotted for three different membranes. In the case of small deflections, the residual stress can be calculated using the linear term of Eq. (10):

$\mathrm{F}=\frac{\mathrm{t} \sigma_{0}}{8 \alpha \beta^{2} \mathrm{~g}^{\prime}\left(\mathrm{k}_{0}\right)} \mathrm{h}$

Then, the stiffness $S_{0}=F / h$ is equal to the slope at the origin of each curve and $\sigma_{0}$ is given by:

$$
\sigma_{0}=8 \alpha \beta^{2} \mathrm{~g}^{\prime}\left(\mathrm{k}_{0}\right) \mathrm{S}_{0} / \mathrm{t}
$$

It is interesting to notice that if the values of $\mathrm{k}_{0}$ are sufficiently large, $\mathrm{k}_{0}>300, \mathrm{~g}^{\prime}\left(\mathrm{k}_{0}\right)$ is approximately equal to $2.51 \mathrm{k}_{0}{ }^{1 / 7}$, function which evolves very slowly with $\mathrm{k}_{0}$, and then:

$$
\mathrm{F}=\frac{\mathrm{t} \sigma_{0}}{8 * 2.51 \alpha \beta^{2}}\left(\frac{\beta^{2} \mathrm{t}^{2} \mathrm{E}}{12\left(1-v^{2}\right) \mathrm{a}^{2} \sigma_{0}}\right)^{\frac{1}{14}} \mathrm{~h}=\mathrm{At}^{1+1 / 7} \sigma_{0}{ }^{1-1 / 14} \mathrm{~h}
$$

A is a constant which depends on the membrane shape ( $a$ and $n$ ) and the Young's modulus $E$ of the material. From the relation (14a) it is easily shown that:

$$
\sigma_{0}=\left(\frac{S_{0}}{A}\right)^{1.077} \frac{1}{t^{1.23}}
$$

(14b).

This relation is a good approximation of the set of equations (6), (8) and (9) when $\mathrm{k}_{0}>300$.

Fig. 9: Examples of experimental results by the point deflection method using a nanoindenter.

Table 3 summarizes the results obtained from these samples according to the previous graph. The values of $\mathrm{g}\left(\mathrm{k}_{0}\right), \mathrm{k}_{0}$ and $\sigma_{0}$ (Eqs 8 and 9) have been calculated using a Young's modulus of $220 \mathrm{GPa}$ according to the bulge test result.

Table 3: Results by point deflection method with the nano-indenter. 
The measured stiffnesses are $8 \times 10^{2}$ to $2 \times 10^{4}$ times higher than those for unstressed membranes $\left(\mathrm{g}\left(\mathrm{k}_{0}\right)=1\right)$ which make measurements possible. The residual stress values $\sigma_{0}$ for $\mathrm{Si}_{3} \mathrm{~N}_{4}(\mathrm{~W} 1)$ and $\mathrm{Si}_{3} \mathrm{~N}_{4} / \mathrm{SiO}_{2}(\mathrm{~W} 2)$ are $343<\sigma_{0}<356 \mathrm{MPa}$ and $43<\sigma_{0}<43.7 \mathrm{MPa}$, respectively.

Because of the tensile residual stresses, experimental $\mathrm{F}$ versus $\mathrm{h}$ curves given in Fig. 9 are almost linear. Then, the Young's modulus cannot be precisely determined using the $F / h=f$ $\left(\mathrm{h}^{2}\right)$ normalized representation. Moreover, the inaccuracy of the $\eta$ coefficient value $\left(\approx 1.9 \times 10^{-}\right.$

2, Eq.7) makes the determination hazardous. An attempt has been made on the less linear curve to calculate $\mathrm{E}$ for a $(1 \mathrm{~mm} \times 2 \mathrm{~mm})$ bilayer membrane with $\mathrm{h} / \mathrm{t}<5$. With $\mathrm{E}_{\mathrm{SiO} 2}=80 \mathrm{GPa}$, a value of $\mathrm{E} \approx 201 \mathrm{GPa}$ has been found whereas the expected value was $\mathrm{E} \approx 157 \mathrm{GPa}$.

Using the nanoindenter, few membranes with large dimensions ( $2 \mathrm{~mm} \times 2 \mathrm{~mm}$ or more) were broken when the contact is established and thus could not be characterized. Indeed, the nanoindenter did not detect these membranes with very low stiffness. That is why, in this work, the point deflection method has been adapted using an AFM in spectrometry mode (see Fig. 2) because it is more sensitive to the very low stiffnesses.

\subsubsection{AFM measurements}

Firstly, the AFM cantilever stiffness $S_{c}$ was determined on the membrane's frame. To do that, the $\mathrm{F}=\mathrm{f}(\mathrm{h})$ curve is determined on the rigid frame ( $\mathrm{Si})$ and thus only the AFM cantilever is deformed; in this case $S_{c}=F / h$. It was found $S_{c} \approx 51.2 ~ N . m^{-1}$ which is in the range given by the manufacturer $\left(42<\mathrm{S}_{\mathrm{c}}<54 \mathrm{~N} \cdot \mathrm{m}^{-1}\right)$. Then, the coupled stiffness $\mathrm{S}$ of the AFM cantilever in contact with the membrane was measured from the slope of the $\mathrm{F}=\mathrm{f}(\mathrm{h})$ curves (Figs. 10 and 11) and the stiffness $S_{0}$ of the membrane was calculated from: $1 / S=1 / S_{0}+1 / S_{c}$. Currently, AFM measurements have been performed on monolayer $\mathrm{Si}_{3} \mathrm{~N}_{4}$ and bilayer $\mathrm{Si} 3 \mathrm{~N}_{4} / \mathrm{SiO}_{2}$ membranes. For example, Fig. 10 and Fig. 11 show experimental linear force-displacement curves obtained for $3 \mathrm{~mm}$ x $3 \mathrm{~mm} \mathrm{Si}{ }_{3} \mathrm{~N}_{4}$ membrane ( $\mathrm{t}=104 \mathrm{~nm}, 4$ measurements $)$ and $1 \mathrm{~mm} \mathrm{x}$ $2 \mathrm{~mm}$ bilayer membrane (100 $\mathrm{nm} \mathrm{Si}_{3} \mathrm{~N}_{4}$ on $94 \mathrm{~nm} \mathrm{SiO} 2,1$ measurement).

We can observe the good results reproducibility from one test to another (Fig. 10) and a slight difference of slope $\mathrm{S}$ between load and unload (Fig. 11). This slight difference is perhaps due to the pull-of force whose effect is clearly visible at the beginning of the contact and at the loss of contact with the membrane (Figs 10 and 11). However, this difference is smaller than the reproducibility and the uncertainties values reported in Tables 6 and 7. 
The extracted values of $S_{0}, g\left(k_{0}\right), k_{0}$ and $\sigma_{0}$ are given in Table 4 and Table 5 for the bilayer and monolayer membranes, respectively.

Fig. 10 Examples of experimental results $\mathrm{F}=f(h)$ by $A F M$ on square monolayer $\mathrm{Si}_{3} \mathrm{~N}_{4}$ membrane.

Fig. 11: Examples of experimental results $\mathrm{F}=f(h)$ by AFM on rectangular bilayer membrane.

Table 4: Results by point deflection method using the AFM on $\mathrm{Si}_{3} \mathrm{~N}_{4} / \mathrm{SiO}_{2}$ membranes.

Table 5: Results by point deflection method using the AFM on $\mathrm{Si}_{3} \mathrm{~N}_{4}$ membranes.

Using this method on the samples issued from the wafers 1 and 3, a mean residual stress of $487 \pm 40 \mathrm{MPa}$ has been found on $\mathrm{Si}_{3} \mathrm{~N}_{4}$ membranes and a residual composite stress of $57 \pm 8$ $\mathrm{MPa}(\mathrm{W} 2)$ and $105 \pm 11 \mathrm{MPa}(\mathrm{W} 4)$ has been found on the $\mathrm{Si}_{3} \mathrm{~N}_{4} / \mathrm{SiO}_{2}$ bilayer (Tab. 6 and 7). For these membranes, considering the values of the Young's modulus measured by bulging tests and the residual stress values obtained with the AFM method for the $\mathrm{Si}_{3} \mathrm{~N}_{4}$ films, the calculated values of the $\mathrm{SiO}_{2}$ residual stress for the W2 and W4 wafers are $-398 \mathrm{MPa}$ and -245 $\mathrm{MPa}$, respectively.

Fig.12 shows an example ( $\mathrm{SiO}_{2}+\mathrm{Si}_{3} \mathrm{~N}_{4}$ membrane) of the evolution of the measured $\mathrm{S}$ (membrane + AFM beam) and membrane $S_{0}$ stiffnesses as a function of the eccentricity ratio 2r/a. $\mathrm{a}$ is the lateral dimension of the membrane and $\mathrm{r}$ is the distance from the membrane center to the point where the concentrated load has been applied. $2 \mathrm{r} / \mathrm{a}=1$ corresponds to the edges of the membrane. The measured stiffness is appreciably independent of the $2 \mathrm{r} / \mathrm{a}$ ratio in the range 0-0.4. This result is in agreement with those presented by S. Markutsya et al [26]. Thus, this method is not very sensitive to the accuracy of the position of the applied load when the lateral dimensions of the membrane are large.

Fig. 12: Variation of the measured and membrane stiffnesses as a function of the eccentricity ratio 2 r/a.

\subsection{Comparison of methods}

All experimental results are summarized in Tables 6 and 7 for each studied method. Blank cells indicate that measurements were not usable (not enough sensitivity for the biggest 
membranes with weak stiffness) or that the samples were broken during the experiment. Results scattering, reflecting measurement repeatability (Tabs. 6 and 7), is weak compared to the overall accuracy of the methods mainly determined by geometrical errors. These geometrical errors (membrane thickness, side length) have been estimated lower than $8 \%$ according to the samples tested.

\section{Table 6: Results obtained on monolayers $\mathrm{Si}_{3} \mathrm{~N}_{4}$}

\section{Table 7: Results obtained on bilayers $\mathrm{Si}_{3} \mathrm{~N}_{4} / \mathrm{SiO}_{2}$}

The results that have been obtained from several membranes with different geometries (achieved on two different wafers in the case of the $\mathrm{Si}_{3} \mathrm{~N}_{4}$ films) using the bulge test method are very tight compared to the overall error margin showing that the mechanical properties of $\mathrm{Si}_{3} \mathrm{~N}_{4}$ are appreciably the same between wafers 1 and 3 . However, this is not the case for the residual stress of the bilayer membranes fabricated from W2 and W4 (Young's modulus and residual stress). Almost similar stress values have been found for the bilayer membranes (wafer 2) using either the nanoindenter or the AFM but slightly lower for nanoindenter. It is obvious that lower stress values have been obtained using the nanoindenter, compared to those obtained using the AFM. That is probably due to the fact that the contact detection of the membrane with the nanoindenter is more difficult than with the AFM. Thus, membranes seem to be more flexible under a nanoindenter.

Residual stress values obtained by the bulge test method are significantly lower than those obtained by the AFM point deflection method, 16\% (W3), 7\% (W2) and 6\% (W4) for the mono and bilayer membranes respectively.

Few assumptions can be made to explain this difference. Firstly, during the preparation of the sample for the bulge test experiment, the wax used for sample sealing slightly deforms the membranes (contrary to the case of the point deflection method, as seen in 4.3.2). For example, in the case of a $104 \mathrm{~nm}$ thick $\mathrm{Si}_{3} \mathrm{~N}_{4}$ membrane with lateral dimensions of $2.13 \mathrm{~mm} \mathrm{x}$ $2.13 \mathrm{~mm}$, using the profilometer, we observed a small upward/downward deformation $( \pm 150$ $\mathrm{nm}$ ) caused by the sample sticking (Fig. 13). This deformation might have partly relaxed the membrane stress and could explain the discrepancy between the two experimental methods. A bulge test experiment was made on the same sample $\left(2 \times 2 \mathrm{~mm} \mathrm{Si}{ }_{3} \mathrm{~N}_{4}\right.$ membrane from wafer 3$)$ with two different sticking methods. One using the wax and the other using vacuum grease which does not deform the sample. The residual stresses extracted using wax and vacuum 
grease sticking are $429 \mathrm{MPa}$ and $428 \mathrm{MPa}$, respectively. Thus, the sticking method cannot explain, alone, the stress difference between bulge test and point deflection method.

Fig. 13: Square membrane $(2 a=2 \mathrm{~mm}) 3$ profile before and after sticking using wax.

The difference in stress values between the bulge test and the point deflection method could come also from the $\mathrm{C}_{1}$ and $\mathrm{f}(\mathrm{v})$ coefficients in Eq. 5 (found in the literature) which are perhaps not well appropriate for our very thin membranes (clamping conditions due to the anisotropic wet etching). The bulge test is more sensitive to the clamping deformations under high deflections than point deflection method which induces local low deflections to the membrane center. Now, using the analytical model of D. Maier-Schneider et al. [34] with $\mathrm{C}_{1}=3.45$ (instead of 3.42), the residual stress variation is too small to explain this difference of results between the two experimental methods. The last works on this coefficient give a $\mathrm{C}_{1}$ value about 3.4 [33-36] and to find a residual stress equivalent to the results obtained by point deflection, one would need a $\mathrm{C}_{1}$ coefficient lower than this value $\left(3<\mathrm{C}_{1}<3.4\right)$. Moreover, these slight differences between the two methods could also come from the presence of a film thickness gradient or a stress gradient across each wafer. In this work, a mean thickness value was assumed for each wafer. However, a variation of $5 \mathrm{~nm}$ on the film thickness value allows a variation of 20 to $30 \mathrm{MPa}$ on the residual stress values calculated with the relations corresponding to these different methods.

In conclusion, the point deflection method using an AFM cantilever is well adapted to accurately determine the residual stress because the results are only slightly influenced by sealing, lateral dimensions and the Young's modulus of the membranes (Eq. 13 and Fig. 14). Indeed, with this method, Fig. 14 shows the calculated residual stress on a monolayer and using different $\mathrm{Si}_{3} \mathrm{~N}_{4}$ Young's modulus values $(180<\mathrm{E}<220 \mathrm{GPa})$. A quasi independence between these two mechanical properties is observed (Fig. 14). For the bulge test, in the same case of very small deflections $(\mathrm{h} / \mathrm{t}<0.5)$ as for the AFM, a third term in Eq. $5[19,35-36]$ must be added, which depends of the Young's modulus value, to calculate the residual stress. However with the point deflexion method, the Young's modulus cannot be accurately extracted on these structures because of the very weak deflection amplitude imposed to the membrane. Therefore the bulge test and the point deflection methods are very complementary. 
Figure 14 shows the synthesis of all the experimental determinations obtained in this study by the different methods, i.e.: the residual stress as a function of the measured Young's modulus.

Fig. 14: Synthesis of the experimental results obtained by the different methods. Evolution of the residual stress as a function of the imposed Young's modulus for point deflection method (Case of Si3N4 samples ).

\section{CONCLUSION}

Mechanical properties (Young's modulus and residual stress), of very thin ( $100 \mathrm{~nm}$ ) and large area (few $\mathrm{mm}^{2}$ ) $\mathrm{Si}_{3} \mathrm{~N}_{4}$ and $\mathrm{Si}_{3} \mathrm{~N}_{4} / \mathrm{SiO}_{2}$ membranes, obtained by means of three characterization procedures have been compared.

In spite of very large length to thickness ratio, the membranes present an elastic behaviour even for deflection to thickness ratio greater than 1000. A very good repeatability of the experimental results for each method was obtained so that Young's modulus and residual stress results were extracted with an overall accuracy lower than $10 \%$. The mixture law has been validated for these structures on standard $\mathrm{Si}_{3} \mathrm{~N}_{4} / \mathrm{SiO}_{2}$ bilayers. Therefore, this law could also be applied on even more complex thin elastic multilayers to determine the mechanical properties of each component.

The first characterization procedure, nanoindentation, was found to be limited by the small film thickness. The bulge test is still valid for the studied structures and more appropriate to determine the Young's modulus due to the large membrane deflections. The point deflection method is limited by the very low deflections applied to these structures and only the residual stress can be accurately extracted. Unlike for the bulge test, reliable residual stress results have been found by this method using an AFM probe, because this mechanical parameter weakly depends on the Young's modulus or on the lateral dimensions or on any sample sticking effects. Moreover, using AFM, the tested structures were not deformed by sticking sample.

Both bulge test and point deflection using AFM are complementary methods to obtain mechanical parameters of very thin and low stiffness dielectric layers or bilayers: the bulge test can be used with high deflections to determine the Young's modulus and mean residual stress whereas the point deflection method can be used with low deflections to accurately determine the residual stress. 
Note: A condensed version of this paper has been presented at Transducers XIV/ Eurosensors XXI 2007, Lyon, France

\section{REFERENCES}

1. P. Martins, S. Béclin, S. Brida, S. Metivet, O. Stojanovic, C. Malhaire, Design of bossed silicon membranes for high sensitivity microphone applications, Microsyst. Tech., 13, 1495 (2007).

2. Y. Zhu, H. D. Espinosa, Reliability of capacitive switches at high and low temperatures, Wiley Periodicals, 317 (2004).

3. Z. Lixian, Y. Tongxi, Z. Yapu, Numerical analysis of theorical model of the RF MEMS switches, Acta. Mech. Sinica., 20, 178 (2004).

4. E. Arzt, Size effects in materials due to microstructural and dimensional constraints: A comparative review, Acta. Mater., 46, 5611 (1998).

5. X. Xiang, X. Chen, J. J. Vlassak, The mechanical properties of electroplated $\mathrm{Cu}$ thin films measured by means of the bulge test technique, Mat. Res. Soc. Symp. Proc., 695 (2002).

6. S. Chen, T. V. Baughn, Z. J. Yao, C. L. Goldsmith, A new in situ residual stress measurement method for a MEMS thin fixed-fixed beam structure, J. Microelectro. Syst. 11, 309 (2002).

7. Y. Choi, S. Suresh, Size effects on the mechanical properties of thin polycrystalline metal films on substrates, Acta Mater., 50, 1881 (2002).

8. J. N. Florando, W.D. Nix, A microbeam bending method for studying stress-strain relations for metal thin films on silicon substrates, J. Mech. Phys. Solids, 53, 619 (2005).

9. R. B. King, Elastic analysis of some punch problems for a layered medium, Int. J. Solids Struct., 23, 1657 (1987).

10. J-H. Ahn, E-C. Jeon, Y. Choi, Y-H. Lee, D. Kwon, Derivation of tensile flow properties of thin films using nanoindentation technique, C. Appl. Phys., 2, 525 (2002).

11. R. Saha, W. D. Nix, Effects of the substrate on the determination of the thin film mechanical properties by nanoindentation, Acta Mater., 50, 23 (2002).

12. R.P. Vinci, J.J. Vlassak, Mechanical behaviour of thin films, Annu. Rev. Mater. Sci. 26, 431 (1996).

13. F. J. Von Preissig, Applicability of the classical curvature-stress relation for thin films on plate substrates, J. Appl. Phys., 66, 4262 (1989). 
14. O. Kraft and C. A. Volkert, Mechanical testing of thin films and small structures, Adv. Engng. Mater., 3, 99 (2001).

15. Sharpe, W.N., Jr. Mechanical Properties of MEMS Materials, The MEMS Handbook, CRC Press, Boca Raton, FL, 3-1-3-33 (2001).

16. Y. Xiang, T. Y. Tsui, J. J. Vlassak, A. J. McKerrow, Measuring the elastic modulus and ultimate strength of low-k dielectric materials by means of the bulge test, IEEE international interconnect technology conference, San Francisco CA , USA (2004).

17. M. K. Tripp, C. Stampfer, D. C. Miller, T. Helbling, C. F. Herrmann, C. Hierold, K. Gall, S. M. George, V. M. Bright, The mechanical properties of atomic layer deposited alumina for use in micro- and nano-electromechanical systems, Sens. Actuators A, 130, 419 (2006).

18. S.Hong, T.P. Weihs, J.C. Bravman, D. Nix, Measuring stiffnesses and residual stresses of silicon nitride thin film, J. Electr. Mater., 19, 903 (1990).

19. C. Poilane, P. Delobelle, C. Lexcellent, S. Hayashi, H. Tobushi, Analysis of the mechanical behavior of shape memory polymer membranes by nanoindentation, bulging and point membrane deflection tests, Thin Solid Films, 379, 156 (2000).

20. R.L. Engelstad, N. Tang, E.G. Lovell, Point-deflection method for in-situ stress determination of advanced lithographic masks, Microelectr. Eng.., 61, 271 (2002).

21. M. R. Begleya, T. J. Mackin, Spherical indentation of freestanding circular thin films in the membrane regime, J. Mech. Phys. Solids, 52, 2005 (2004).

22. M. Józwik, P. Delobelle, C. Gorecki, A. Sabac, L. Nieradko, C. Meunier and F. Munnick, Optomechanical characterization of compressively prestressed silicon oxynitride films deposited by plasma-enhanced Chemical vapor deposition on silicon membranes, Thin Solid Films, 468, 84 (2004).

23. J. Thévenet, P. Delobelle, P. Blind, V. Petrini, M. De Labachelerie, 17ième Congrès Français de Mécanique, Troyes, Septembre 2005.

24. R. Zhang, D. Shilo, G. Ravichandran, K. Bhattacharya, Mechanical characterisation of released thin films by contact loading, J. Appl. Mech., 73,730 (2006).

25. Z.C. Lesemana, T.J. Mackin, Indentation testing of axisymmetric freestanding nanofilms using a MEMS load cell, Sens. Actuators, 134, 264 (2007).

26. S. Markutsya, C. Jiang, Y. Pikus, V. V.Tsukruk, Freely suspended layer by layer nanomembranes: testing micromechanical properties, Adv. Funct. Mater., 15, 771 (2005).

27. B. R. Bracio, R. J. Fasching, F. Kohl, J. Krocza, A smart thin film flow sensors for biomedical applications, Proceedings of the 22nd Annual EMBS International Conference, July 23-28, 2000, Chicago IL. 
28. V. Guidi, G. C. Cardinali, L. Dori, G. Faglia, M. Ferroni, G. Martinelli, P Nelli and G. Sberveglieri, Thin film gas sensor implemented on a low power consumption micromachined silicon structure, Sens. Actuators, 49, 88 (1998).

29. H. Watanabe, R. Vendamme, T. Kunitake, Development of fabrication of giant nanomembranes, Bull. Chem. Soc. Jpn., 80, 433 (2007).

30. W. C. Olivier and G. M. Pharr, An improved technique for determining hardness and elastic modulus using load and displacement sensing indentation experiments, J. Mater. Res., 7, 1564 (1992).

31. O. Tabata, K. Kawahata, S. Sugiyama and I. Igarishi, Mechanical property measurements of thin films using load-deflection of composite rectangular membranes, Sens. Actuators, 20, 135 (1989).

32. J. Y. Pan, P. Lin, F. Maseeh and S. D. Senturia, Verification of FEM analysis of loaddeflection methods for measuring mechanical property of thin films, Tech. Digest, IEEE Solid-State Sensor and Actuators Workshop, Hilton Head, S.C., 191, pp. 70-73, (1990).

33. J. Vlassak and W. D. Nix, A new bulge test technique for the determination of the Young's modulus and the Poisson's ratio of the thin films, J. Mater. Res., 7, 3242 (1992).

34. D. Maier-Schneider, J. Maibach and E. Obermeier, A new analytical solution for the loaddeflection of square membranes, J. Microelectromech. Syst., 4, 238 (1995).

35. E. Bonnotte, P. Delobelle, L. Bornier, B. Trolard and G. Tribillon, Two interferometric methods for the mechanical characterisation of thin films by bulging test. Application to silicon single crystal, J. Mater. Res., 12, 2234 (1997).

36. K. Danaie, Membranes micro-usinées par gravure chimique anisotrope: application à la caractérisation des films minces. Thesis , Université Pierre et Marie Curie, Paris VI, (2002)

37. O. R. Shojaei and A. Karimi, Comparison of mechanical properties of TiN thin films using nanoindentation and bulge test, Thin Solid Films, 332, 202 (1998).

38. S. T. Lau, H. L. W. Chan, C. L. Choy, W. Y. Cheung and S. P. Wong, Processing and characterisation of micromachined actuators based on proton-irradiated $\mathrm{P}(\mathrm{VDF}-\mathrm{TrFE})$ copolymer, Integrat. Ferroelect., 69, 375 (2005).

39. J. A. Taylor, The mechanical properties and microstructure of plasma enhanced chemical vapour deposited silicon nitride thin films, J. Vac. Sci. Technol. A, 9, 2464 (1991).

40. M. T. Kim, Influence of substrates on the elastic reaction of films for the microindentation tests, Thin Solid Films, 283, 12 (1996).

41. T.-Y. Zhang, Y.-J. Su, C.-F. Qian, M.-H. Zhao, and L.-Q. Chen, Microbridge testing of silicon nitride thin films deposited on silicon wafers, Acta Mater., 48, 2843 (2000). 
42. R. L. Edwards, G. Coles and W. N. Sharpe, Comparison of tensile and bulge tests for thinfilm silicon nitride, Exp.. Mech., 44, 49 (2004).

43. R. Zhang, D. Shilo, G. Ravichandran and K. Bhattacharya, Mechanical characterization of released thin films by contact loading, J. Appl. Mech., 73, 730 (2006).

44. O. Zohni, G. Buckner, T. Kim, A. Kingon, J. Maranchi and R. Siergiej, Investigation thin film stresses in stacked silicon dioxide / silicon nitride structures and quantifying their effects on frequency response, J. Micromech. Microengng., 17, 1042 (2007). 


\section{Figure Captions}

Fig. 1 Bulge test principle.

Fig. 2: Point deflection method using a nanoindenter (on the left) or an AFM in spectrometry mode (on the right).

Fig. 3: Membranes configurations.

Fig. 4: Membranes after fabrication.

Fig. 5: Optical Interferometer setup.

Fig. 6: Determination of the Young's modulus by nanoindentation.

Fig. 7: Normalized pressure-displacement $\left(P / h=f\left(h^{2}\right)\right)$ curves of $\mathrm{Si}_{3} \mathrm{~N}_{4}$ membranes.

Fig. 8: Normalized pressure-displacement $\left(\mathrm{P} / h=f\left(h^{2}\right)\right)$ curves of $\mathrm{Si}_{3} \mathrm{~N}_{4} / \mathrm{SiO}_{2}$ membranes.

Fig. 9: Examples of experimental results by the point deflection method using a nanoindenter. Fig. 10 Examples of experimental results $\mathrm{F}=f(h)$ by $A F M$ on square monolayer $\mathrm{Si}_{3} \mathrm{~N}_{4}$ membrane.

Fig. 11: Examples of experimental results $\mathrm{F}=f(h)$ by $A F M$ on rectangular bilayer membrane. Fig. 12: Variation of the measured and membrane stiffnesses as a function of the eccentricity ratio 2 r/a.

Fig. 13: Square membrane $(2 a=2 \mathrm{~mm}) 3 D$ profile before and after sticking using wax.

Fig. 14: Synthesis of the experimental results obtained by the different methods. Evolution of the residual stress as a function of the imposed Young's modulus for point deflection method. (Case of Si3N4 samples). 


\section{Table Captions}

Table 1: Values of the $\alpha, \beta$ and $C_{o}$ coefficients for different membrane shapes.

Table 2: Tested samples.

Table 3: Results by point deflection method with the nano-indenter.

Table 4: Results by point deflection method using the AFM on $\mathrm{Si}_{3} \mathrm{~N}_{4} / \mathrm{SiO}_{2}$ membranes.

Table 5: Results by point deflection method using the AFM on $\mathrm{Si}_{3} \mathrm{~N}_{4}$ membranes.

Table 6: Synthesis of the results obtained on monolayers $\mathrm{Si}_{3} \mathrm{~N}_{4}$.

Table 7: Synthesis of the results obtained on the bilayers $\mathrm{Si}_{3} \mathrm{~N}_{4} / \mathrm{SiO}_{2}$. 
TABLES

\begin{tabular}{|c|c|c|c|}
\hline shape & $\alpha$ & $\beta$ & $\mathrm{C}_{\mathrm{o}}$ \\
\hline circular & $4.9710^{-3}$ & 2 & 7.48 \\
\hline square $\mathrm{b} / \mathrm{a}=1$ & $5.6110^{-3}$ & 1.86 & 6.08 \\
\hline rectangular $\mathrm{b} / \mathrm{a}=2$ & $7.2210^{-3}$ & 1.58 & 4.65 \\
\hline rectangular $\mathrm{b} / \mathrm{a}=4$ & $7.2410^{-3}$ & 1.58 & - \\
\hline rectangular $\mathrm{b} / \mathrm{a}=\infty$ & $7.2510^{-3}$ & 1.59 & - \\
\hline
\end{tabular}

Table 1: Values of the $\alpha, \beta$ and $C_{o}$ coefficients for different membrane shapes. 


\begin{tabular}{|c|c|c|c|c|}
\hline & Membranes & $\begin{array}{c}2 \mathrm{a} \times 2 \mathrm{~b} \\
\left(\mathrm{~mm}^{2}\right)\end{array}$ & $\begin{array}{c}\text { Nb. of } \\
\text { samples }\end{array}$ & $\begin{array}{c}\text { Thickness } \\
\text { (nm) }\end{array}$ \\
\hline Wafer 1 & $\mathrm{Si}_{3} \mathrm{~N}_{4}$ & $\begin{array}{l}\cdot 1 \times 2 \\
\cdot-1.5 \times 1.5 \\
\cdot 2 \times 2 \\
\cdot 3 \times 3\end{array}$ & $\begin{array}{l}\times 3 \\
\times 5 \\
\times 5 \\
\times 3\end{array}$ & 106 \\
\hline Wafer 2 & $\mathrm{Si}_{3} \mathrm{~N}_{4} / \mathrm{SiO}_{2}$ & $\begin{array}{l}\cdot 1 \times 2 \\
\cdot 1.5 \times 1.5 \\
\cdot 2 \times 2\end{array}$ & $\begin{array}{r}\times 4 \\
\times 1 \\
\times 4\end{array}$ & $100.2+94.4$ \\
\hline Wafer 3 & $\mathrm{Si}_{3} \mathrm{~N}_{4}$ & $\begin{array}{l}\text { - } 3.1 \times 3.1 \\
\text { - } 2.13 \times 2.13 \\
\text { - } 1.14 \times 2.13\end{array}$ & $\begin{array}{l}\times 1 \\
\times 1 \\
\times 1\end{array}$ & 104 \\
\hline Wafer 4 & $\mathrm{Si}_{3} \mathrm{~N}_{4} / \mathrm{SiO}_{2}$ & $\begin{array}{l}\cdot 0.67 \times 0.67 \\
\cdot 0.9 \times 0.9 \\
\cdot-1.89 \times 1.89 \\
\cdot 1.39 \times 7.8 \\
\cdot 0.27 \times 3.28\end{array}$ & 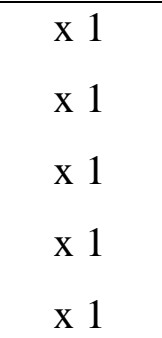 & $90+98$ \\
\hline
\end{tabular}

Table 2: Tested samples. 


\begin{tabular}{|l|c|c|c|c|c|c|c|}
\hline \multicolumn{1}{|c|}{ Samples } & $\begin{array}{c}2 \mathrm{a} \times 2 \mathrm{~b} \\
\left(\mathrm{~mm}^{2}\right)\end{array}$ & $\mathrm{t}(\mathrm{nm})$ & $\begin{array}{c}\mathrm{Nb} \text { samples } \\
\times \mathrm{Nb} \\
\text { measures }\end{array}$ & $\mathrm{S}_{0}(\mathrm{~N} / \mathrm{m})$ & $\mathrm{g}\left(\mathrm{k}_{0}\right)\left(\times 10^{-5}\right)$ & $\mathrm{k}_{0}$ & $\begin{array}{c}\sigma_{0} \\
(\mathrm{MPa})\end{array}$ \\
\hline$(\mathrm{W} 1) \mathrm{Si}_{3} \mathrm{~N}_{4}$ & $1 \times 2$ & 106 & $1 \times 3$ & $40 \pm 3$ & 8.3 & 792 & 356 \\
\hline$(\mathrm{W} 1) \mathrm{Si}_{3} \mathrm{~N}_{4}$ & $1.5 \times 1.5$ & 106 & $1 \times 1$ & 34.6 & 5.48 & 904 & 343 \\
\hline$(\mathrm{W} 2) \mathrm{Si}_{3} \mathrm{~N}_{4} / \mathrm{SiO}_{2}$ & $1 \times 2$ & $100+94$ & $2 \times 3$ & $11.5 \pm 0.18$ & 124 & 181 & 43 \\
\hline
\end{tabular}

Table 3: Results by point deflection method with the nano-indenter. 


\begin{tabular}{|l|c|c|c|c|c|}
\hline $\begin{array}{c}\text { Membrane (a x b) } \\
\mathrm{Si}_{3} \mathrm{~N}_{4} / \mathrm{SiO}_{2}\end{array}$ & $\mathrm{t}(\mathrm{nm})$ & $\mathrm{S}_{0}(\mathrm{~N} / \mathrm{m})$ & $\mathrm{g}\left(\mathrm{k}_{0}\right)\left(\times 10^{-5}\right)$ & $\mathrm{k}_{0}$ & $\sigma_{0}(\mathrm{MPa})$ \\
\hline (W2) $1 \times 2$ & $100+94$ & $14.4 \pm 0.6$ & 97.9 & 206 & $53.3 \pm 2.6$ \\
\hline$(\mathrm{W} 2) 2 \times 2$ & $100+94$ & $13.5 \pm 0.9$ & 31.8 & 375 & $61 \pm 3.6$ \\
\hline (W4) $0.67 \times 0.67$ & $90+98$ & 28.5 & 122 & 182 & $120 \pm 5$ \\
\hline (W4) $0.9 \times 0.9$ & $90+98$ & 22.5 & 86.4 & 220 & $98 \pm 5$ \\
\hline (W4) $1.89 \times 1.89$ & $90+98$ & 21.7 & 20.1 & 485 & $107 \pm 5$ \\
\hline (W4) $1.39 \times 7.8$ & $90+98$ & 20.0 & 31.5 & 375 & $92 \pm 5$ \\
\hline (W4) $0.27 \times 3.28$ & $90+98$ & 32.4 & 515 & 80 & $110 \pm 5$ \\
\hline
\end{tabular}

Table 4: Results by point deflection method using the AFM on $\mathrm{Si}_{3} \mathrm{~N}_{4} / \mathrm{SiO}_{2}$ membranes. 


\begin{tabular}{|l|c|c|c|c|c|}
\hline $\begin{array}{c}\text { Membranes (a x b) } \\
\mathrm{Si}_{3} \mathrm{~N}_{4}\end{array}$ & $\mathrm{t}(\mathrm{nm})$ & $\mathrm{S}_{0}(\mathrm{~N} / \mathrm{m})$ & $\mathrm{g}\left(\mathrm{k}_{0}\right)\left(\times 10^{-5}\right)$ & $\mathrm{k}_{0}$ & $\sigma_{0}(\mathrm{MPa})$ \\
\hline (W3) $1.14 \times 2.13$ & 104 & 50.9 & 4.68 & 1076 & $480 \pm 9$ \\
\hline (W3) $2.13 \times 2.13$ & 104 & 47.49 & 1.85 & 1763 & $516 \pm 29$ \\
\hline (W3) $3.1 \times 3.1$ & 104 & 44.14 & 0.93 & 2450 & 465 \\
\hline
\end{tabular}

Table 5: Results by point deflection method using the AFM on $\mathrm{Si}_{3} \mathrm{~N}_{4}$ membranes. 


\begin{tabular}{|c|c|c|c|c|c|c|}
\hline & & & & \multicolumn{3}{|c|}{$\sigma_{0}(\mathrm{MPa})$} \\
\hline \multirow{2}{*}{$\mathrm{Si}_{3} \mathrm{~N}_{4}$} & \multirow{2}{*}{$\begin{array}{c}\text { Membranes } \\
2 \mathrm{a} \times 2 \mathrm{~b}\left(\mathrm{~mm}^{2}\right)\end{array}$} & \multirow{2}{*}{$\mathrm{t}(\mathrm{nm})$} & \multirow{2}{*}{$\begin{array}{c}\text { E (GPa) } \\
\text { Bulge Test }\end{array}$} & \multirow{2}{*}{ Bulge Test } & \multicolumn{2}{|c|}{ Point Deflection } \\
\hline & & & & & nanoindenter & AFM \\
\hline \multirow{4}{*}{ Wafer 1} & $1 \times 2$ & 106 & $218 \pm 2$ & $403 \pm 9$ & $356 \pm 27$ & - \\
\hline & $1.5 \times 1.5$ & 106 & $212 \pm 6$ & $387 \pm 7$ & $343 \pm 15$ & - \\
\hline & $2 \times 2$ & 106 & $217 \pm 2$ & $405 \pm 6$ & - & - \\
\hline & $3 \times 3$ & 106 & $231 \pm 2$ & $418 \pm 5$ & - & - \\
\hline \multirow{3}{*}{ Wafer 3} & $1.14 \times 2.13$ & 104 & 215 & 418 & - & $480 \pm 9$ \\
\hline & $2.13 \times 2.13$ & 104 & 214 & 409 & - & $516 \pm 29$ \\
\hline & $3.1 \times 3.1$ & 104 & 209 & 439 & - & 465 \\
\hline $\begin{array}{c}\text { Average } \\
\text { values } \\
\text { (W1+W3) }\end{array}$ & - & - & $217 \pm 14$ & $411 \pm 30$ & $349 \pm 28$ & $487 \pm 40$ \\
\hline
\end{tabular}

Table 6: Synthesis of the results obtained on monolayers $\mathrm{Si}_{3} \mathrm{~N}_{4}$. 


\begin{tabular}{|c|c|c|c|c|c|c|}
\hline \multirow[b]{3}{*}{$\mathrm{Si}_{3} \mathrm{~N}_{4} / \mathrm{SiO}_{2}$} & \multirow{3}{*}{$\begin{array}{c}\text { Membranes } \\
2 \mathrm{a} \times 2 \mathrm{~b} \\
\left(\mathrm{~mm}^{2}\right)\end{array}$} & \multirow[b]{3}{*}{$\mathrm{t}(\mathrm{nm})$} & \multirow{3}{*}{$\begin{array}{c}\text { E (GPa) } \\
\text { Bulge Test }\end{array}$} & \multicolumn{3}{|c|}{$\sigma_{0}(\mathrm{MPa})$} \\
\hline & & & & \multirow[b]{2}{*}{ Bulge Test } & \multicolumn{2}{|c|}{ Point Deflection } \\
\hline & & & & & nanoindenter & AFM \\
\hline \multirow{4}{*}{ Wafer 2} & $1 \times 2$ & 194.6 & $159 \pm 2$ & $51 \pm 1$ & $43 \pm 1$ & $53 \pm 3$ \\
\hline & $1.5 \times 1.5$ & 194.6 & 155 & 53 & - & - \\
\hline & $2 \times 2$ & 194.6 & $157 \pm 1$ & $54 \pm 5$ & - & $61 \pm 4$ \\
\hline & $3 \times 3$ & 194.6 & - & - & - & - \\
\hline $\begin{array}{c}\text { Average values } \\
\text { (W2) }\end{array}$ & - & - & $157 \pm 3$ & $53 \pm 5$ & $43 \pm 1$ & $57 \pm 8$ \\
\hline \multirow{5}{*}{ Wafer 4} & $0.67 \times 0.67$ & 188 & 150 & 114 & - & $120 \pm 5$ \\
\hline & $0.9 \times 0.9$ & 188 & 144 & 69 & - & $98 \pm 5$ \\
\hline & $1.89 \times 1.89$ & 188 & 147 & 105 & - & $107 \pm 5$ \\
\hline & $1.39 \times 7.8$ & 188 & 139 & 103 & - & $92 \pm 5$ \\
\hline & $0.27 \times 3.28$ & 188 & 122 & 106 & - & $110 \pm 5$ \\
\hline \multirow[t]{2}{*}{$\begin{array}{c}\text { Average values } \\
\text { (W4) }\end{array}$} & - & - & $141 \pm 11$ & $99 \pm 16$ & - & $105 \pm 11$ \\
\hline & \multicolumn{6}{|c|}{$\mathrm{E}$ and $\sigma_{0}$ for the $\mathrm{SiO}_{2}$ films } \\
\hline \multirow{2}{*}{ Calculated values } & $\mathrm{W}(2)$ & - & 94 & -327 & - & -398 \\
\hline & $\mathrm{W}(4)$ & - & 71 & -187 & - & -245 \\
\hline
\end{tabular}

Table 7: Synthesis of the results obtained on bilayers $\mathrm{Si}_{3} \mathrm{~N}_{4} / \mathrm{SiO}_{2}$.. 

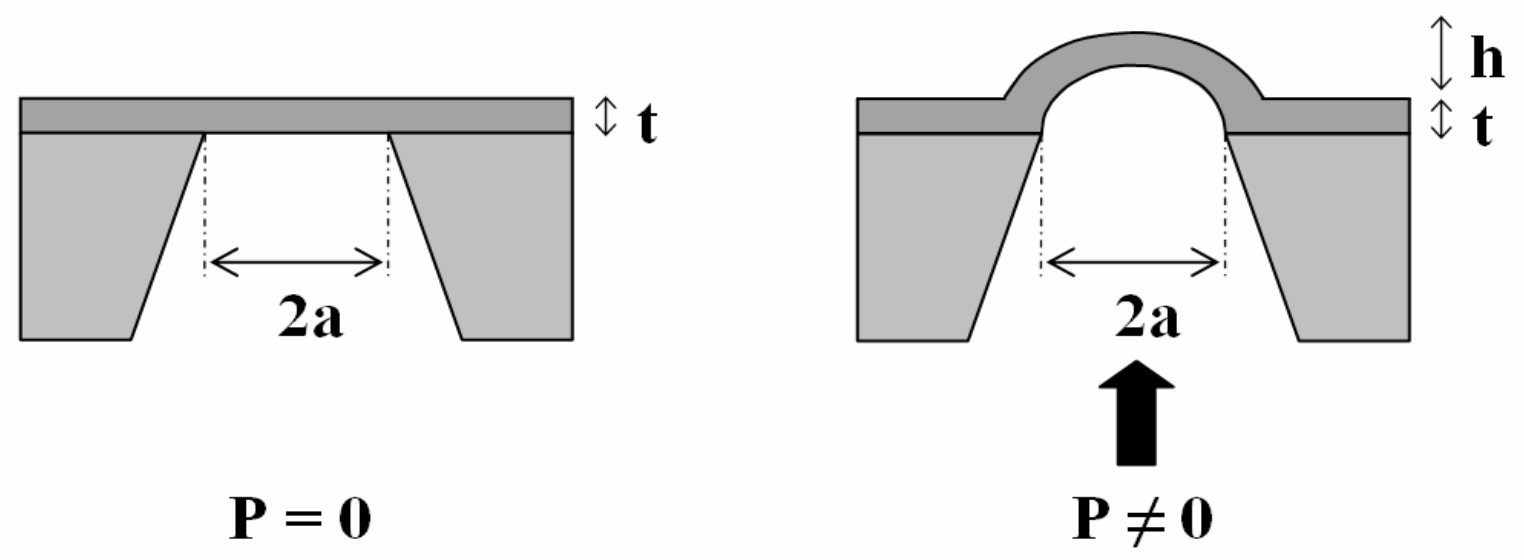

Fig. 1 

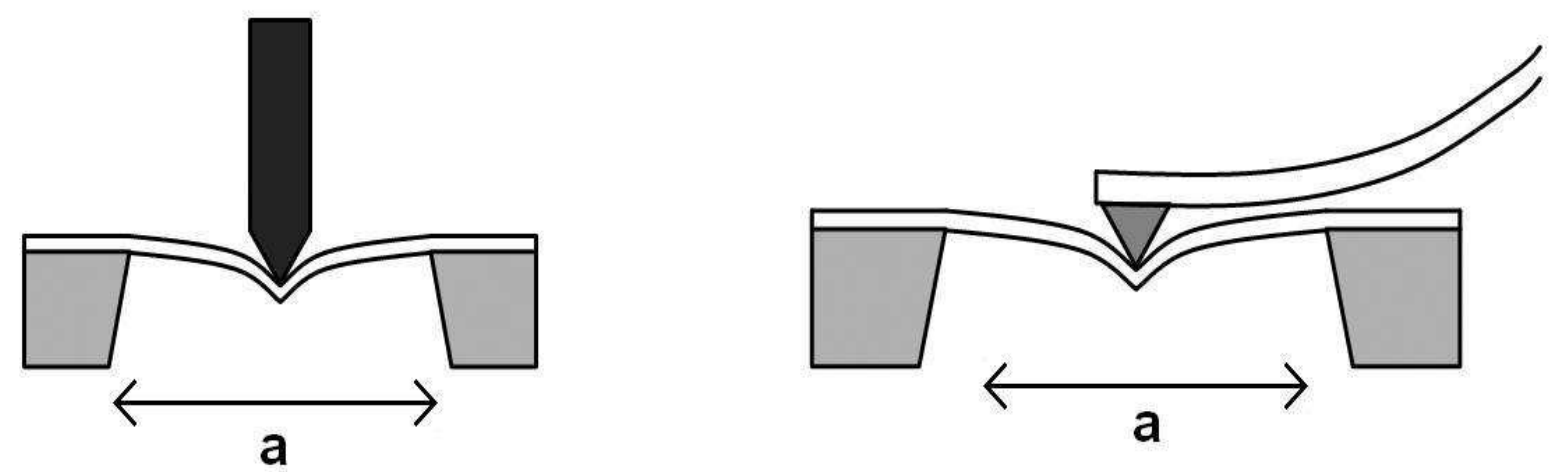

Fig .2 
(1)

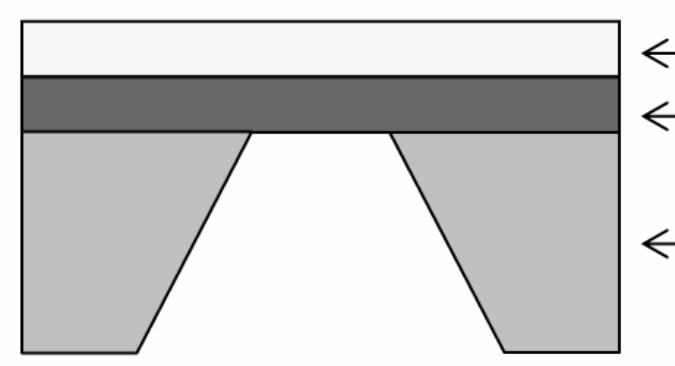

Fig .3
(2)

$\mathrm{Si}_{3} \mathbf{N}_{4} \rightarrow$ $\mathrm{SiO}_{2} \rightarrow$ $\mathrm{Si} \rightarrow$

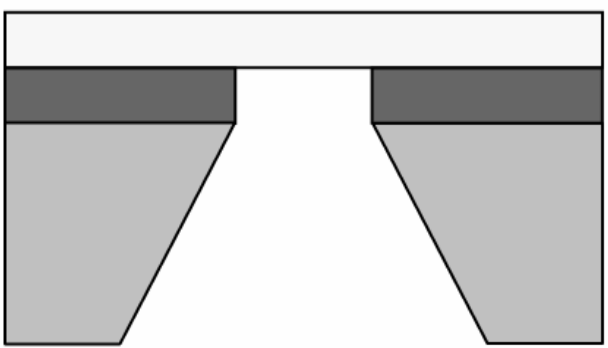




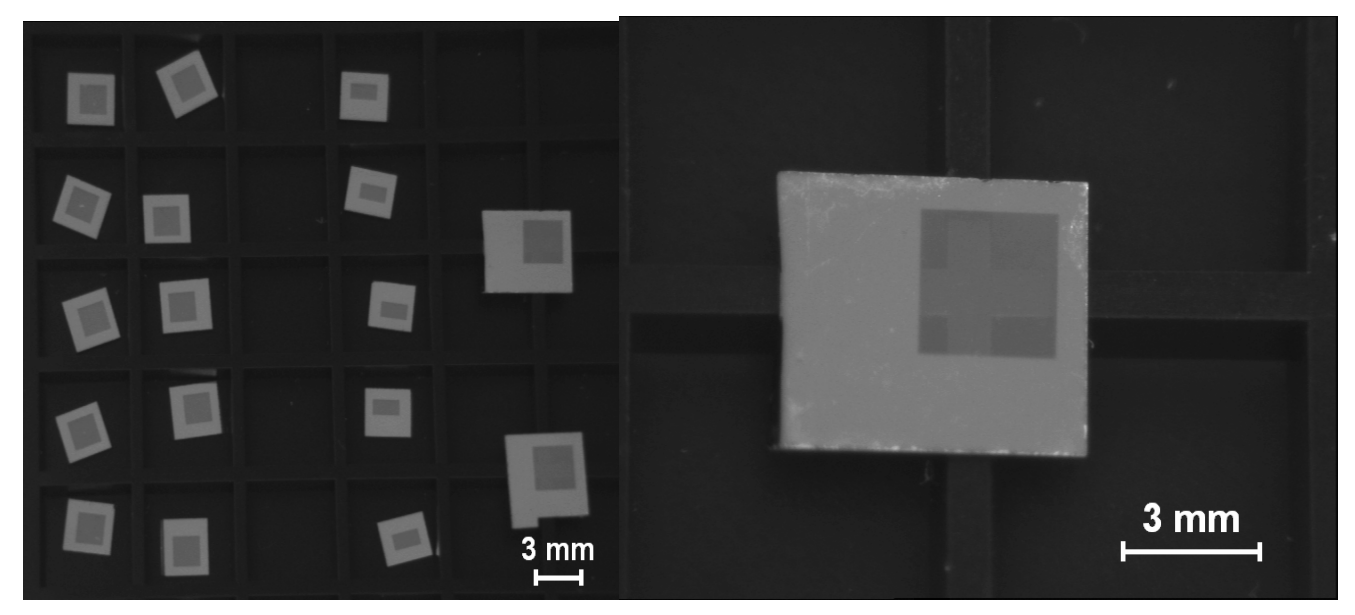

Fig .4 

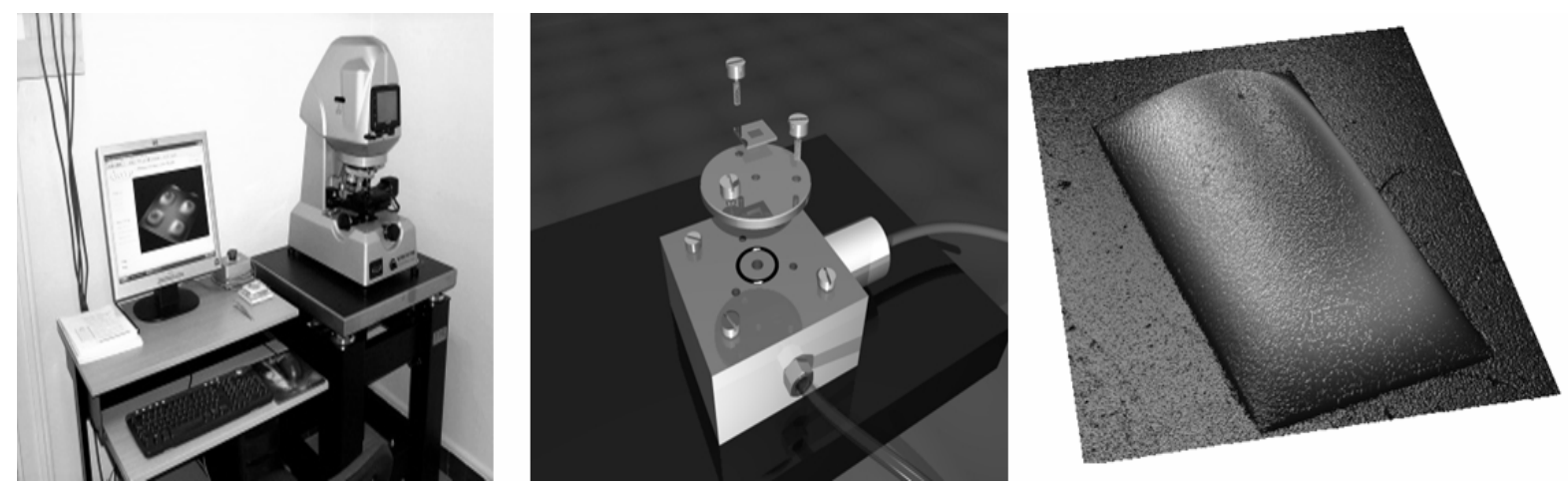

Fig .5 


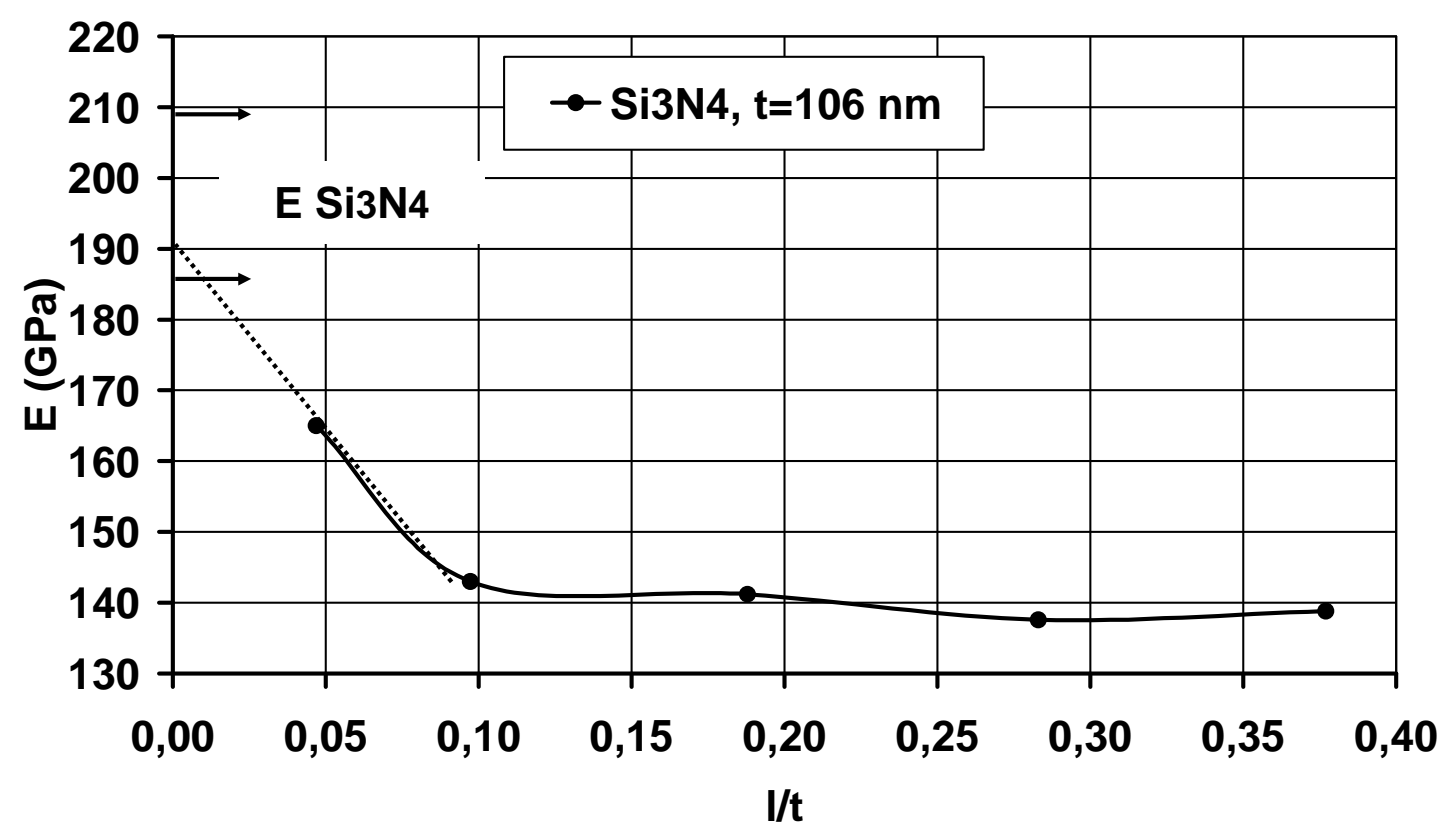

Fig.6 


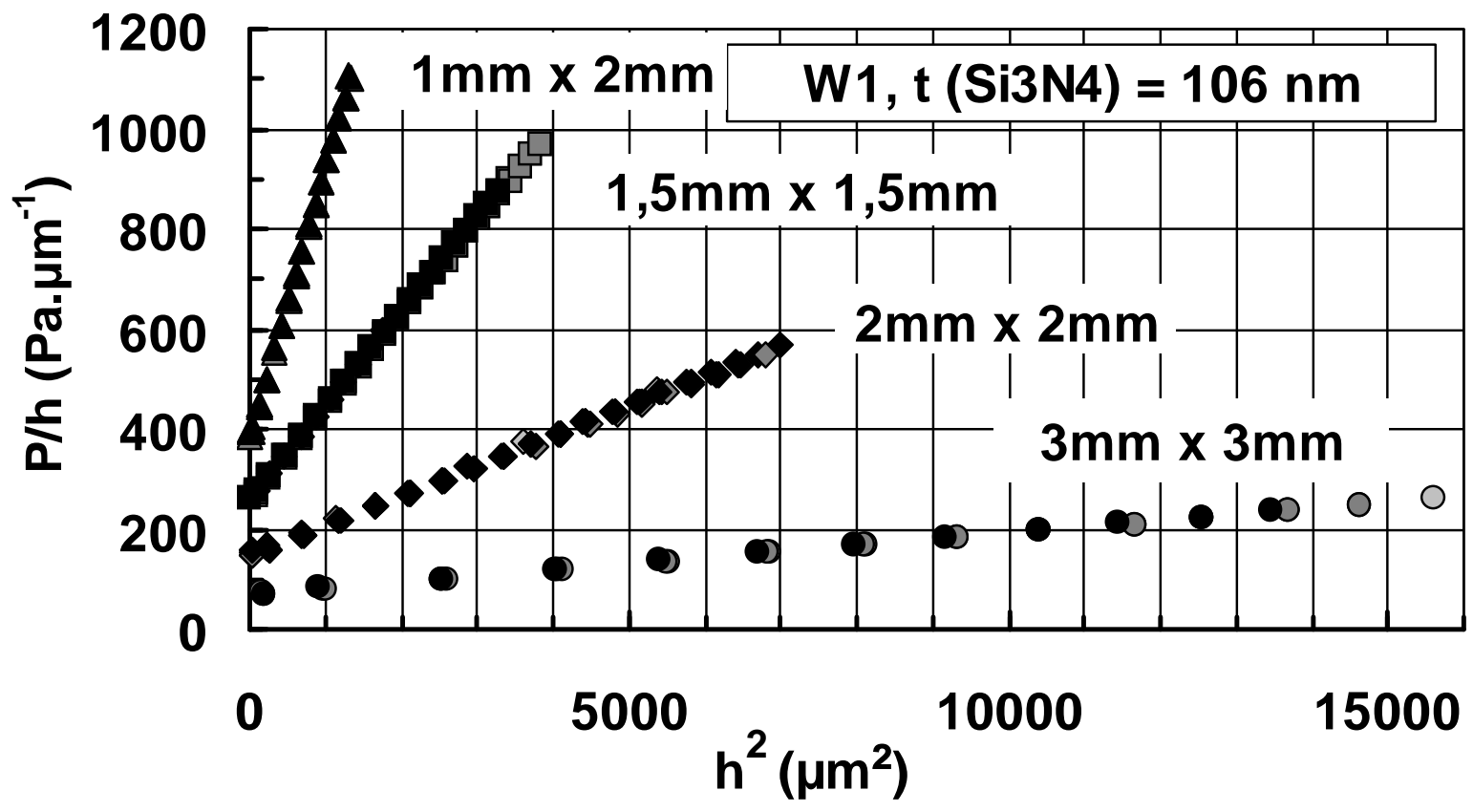

Fig .7 


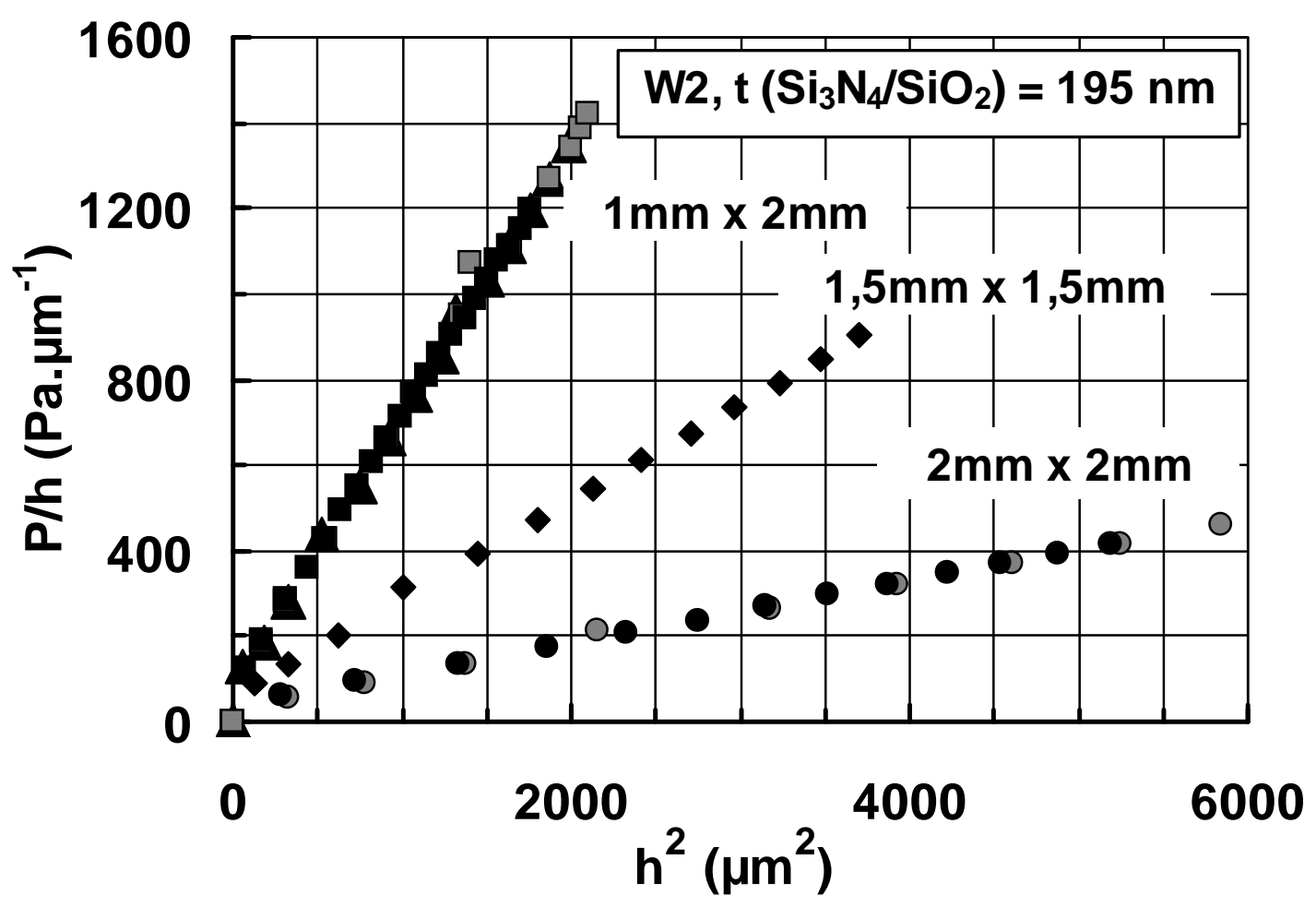

Fig .8 


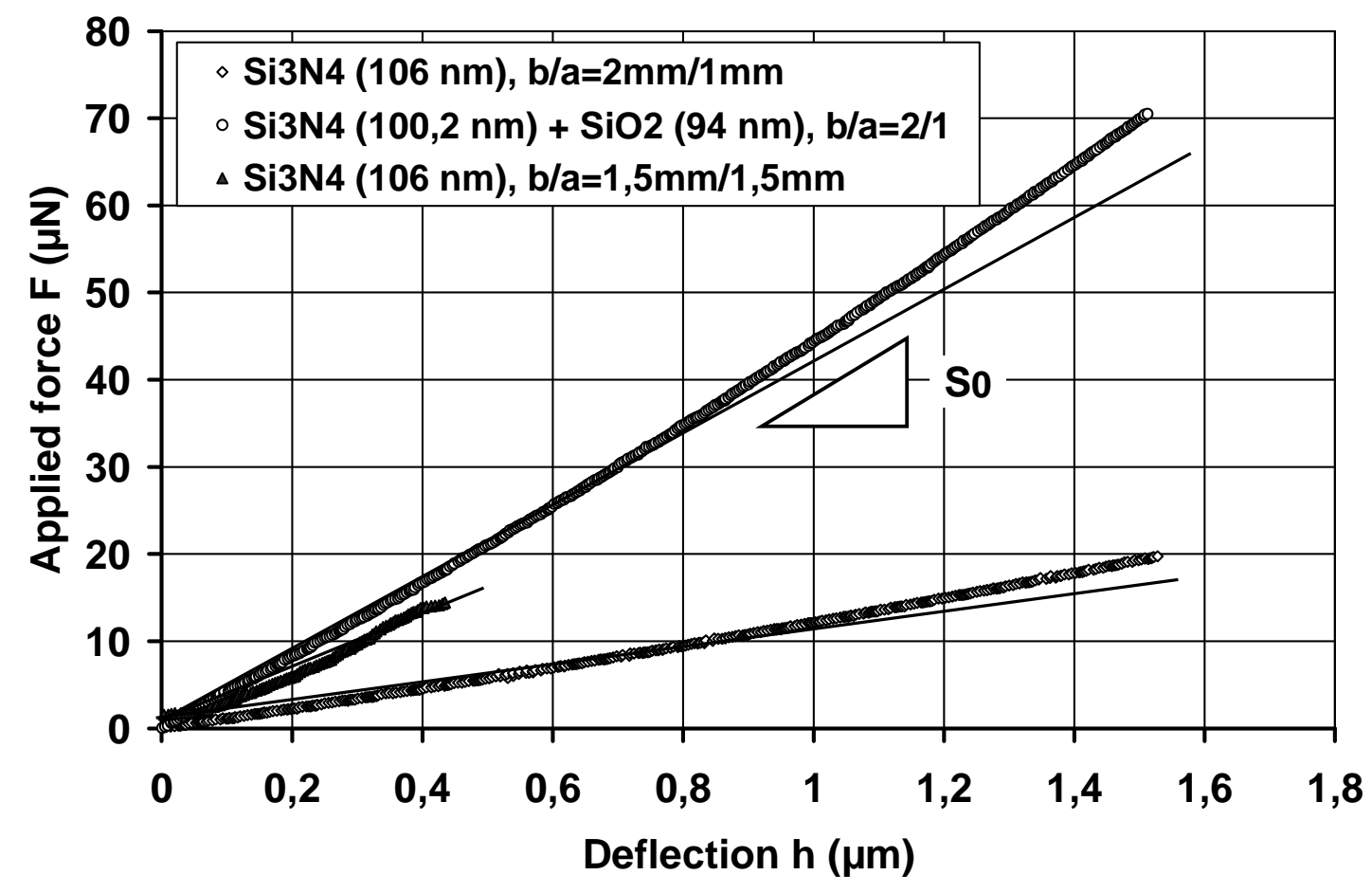

Fig .9 


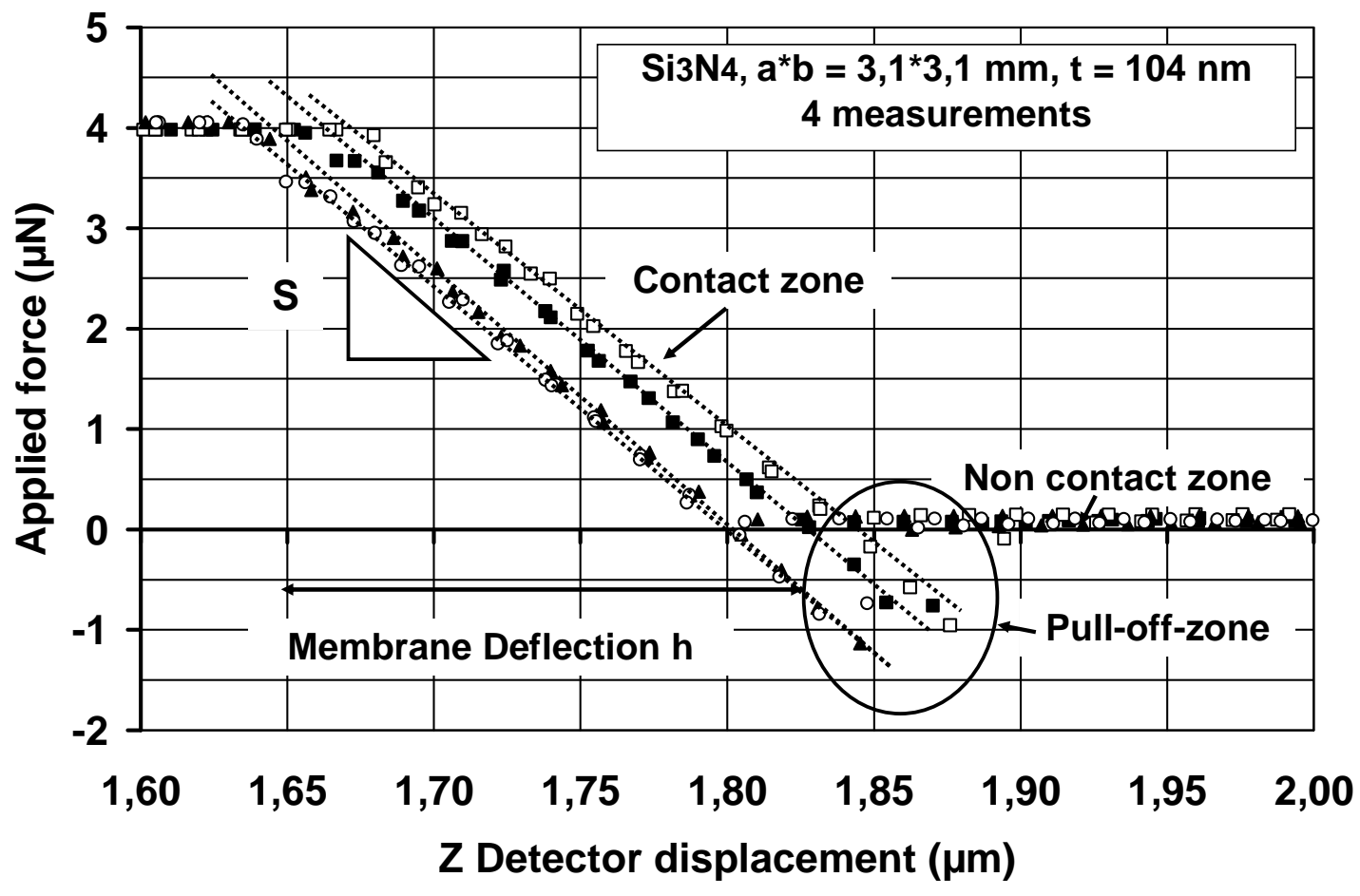

Fig .10 


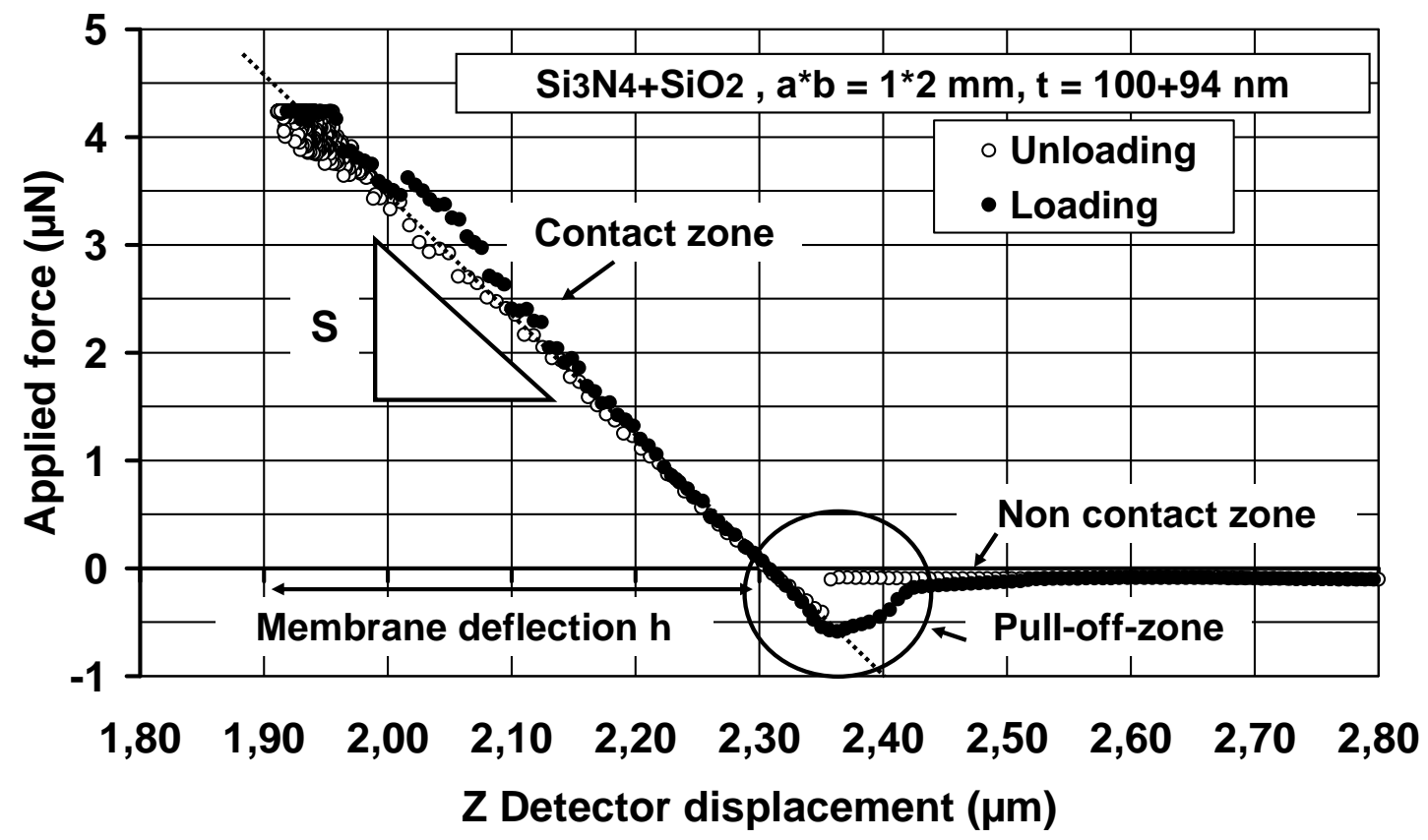

Fig .11 


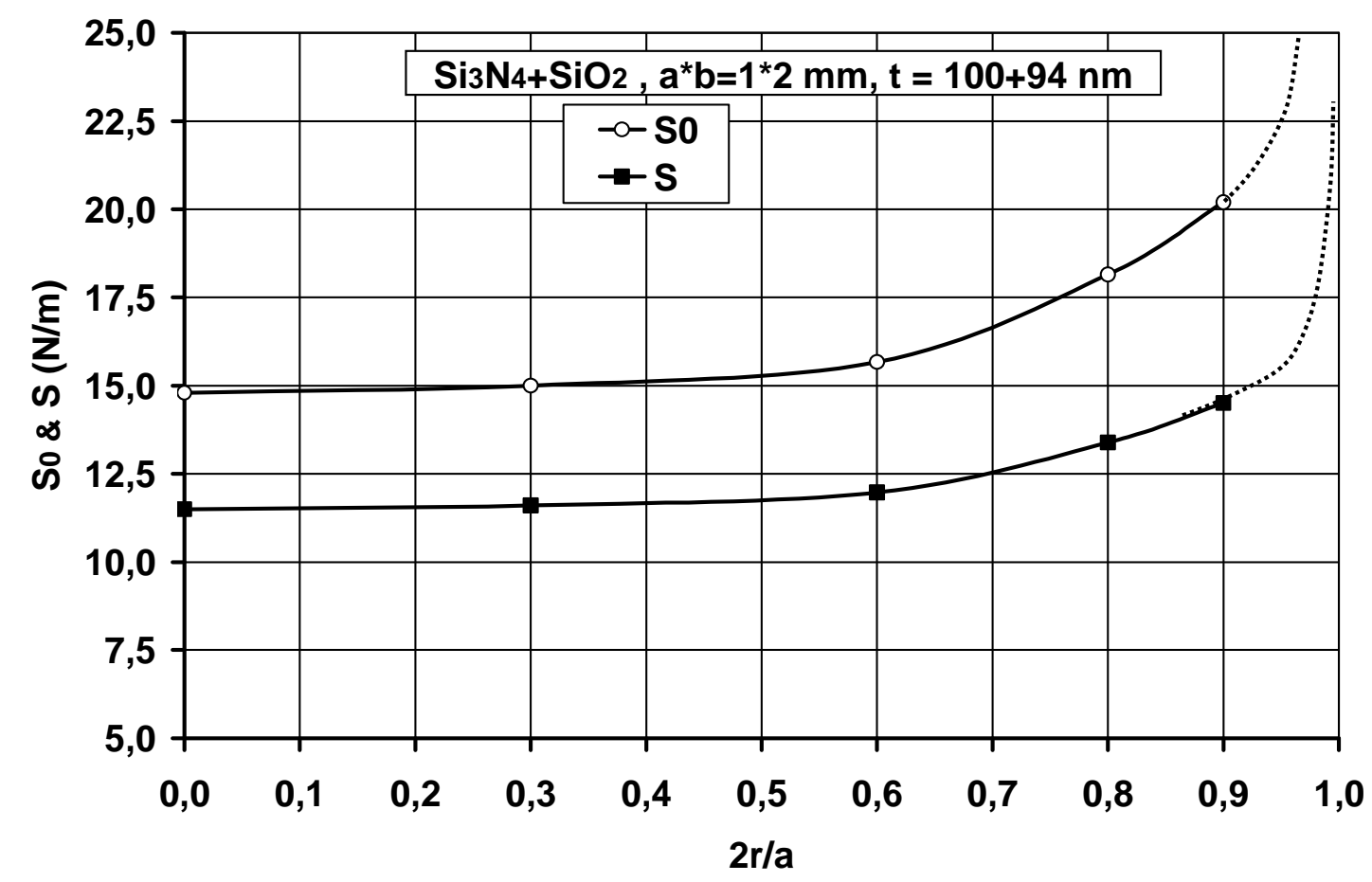

Fig.12 

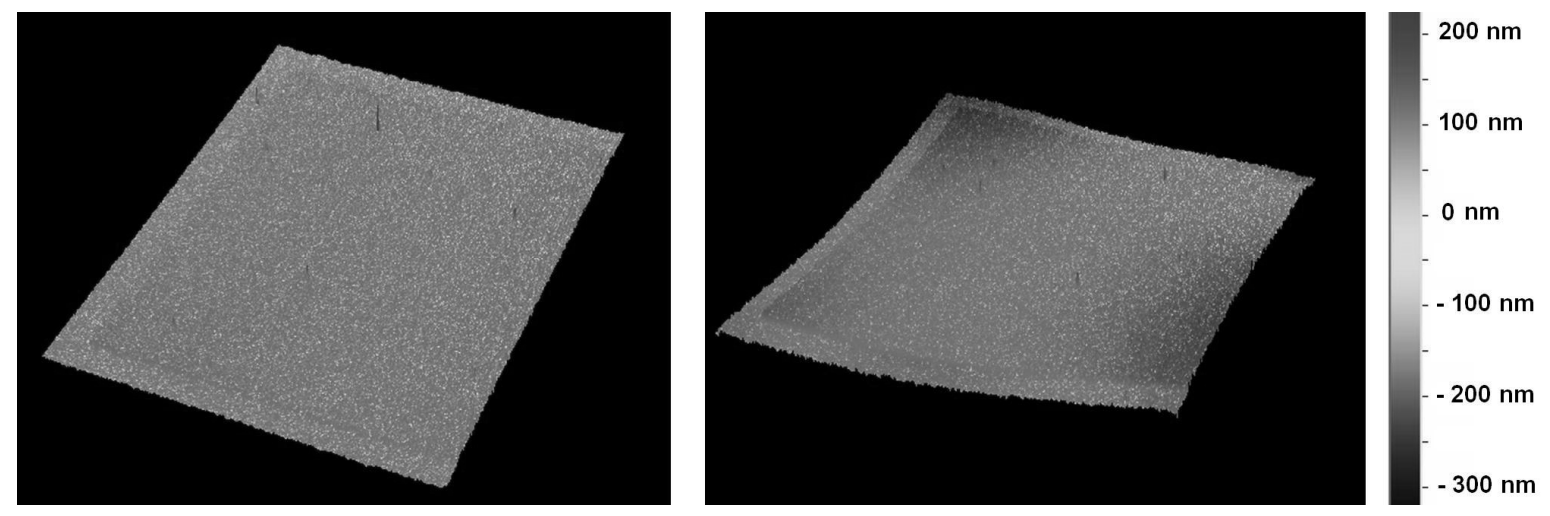

Fig. 13 


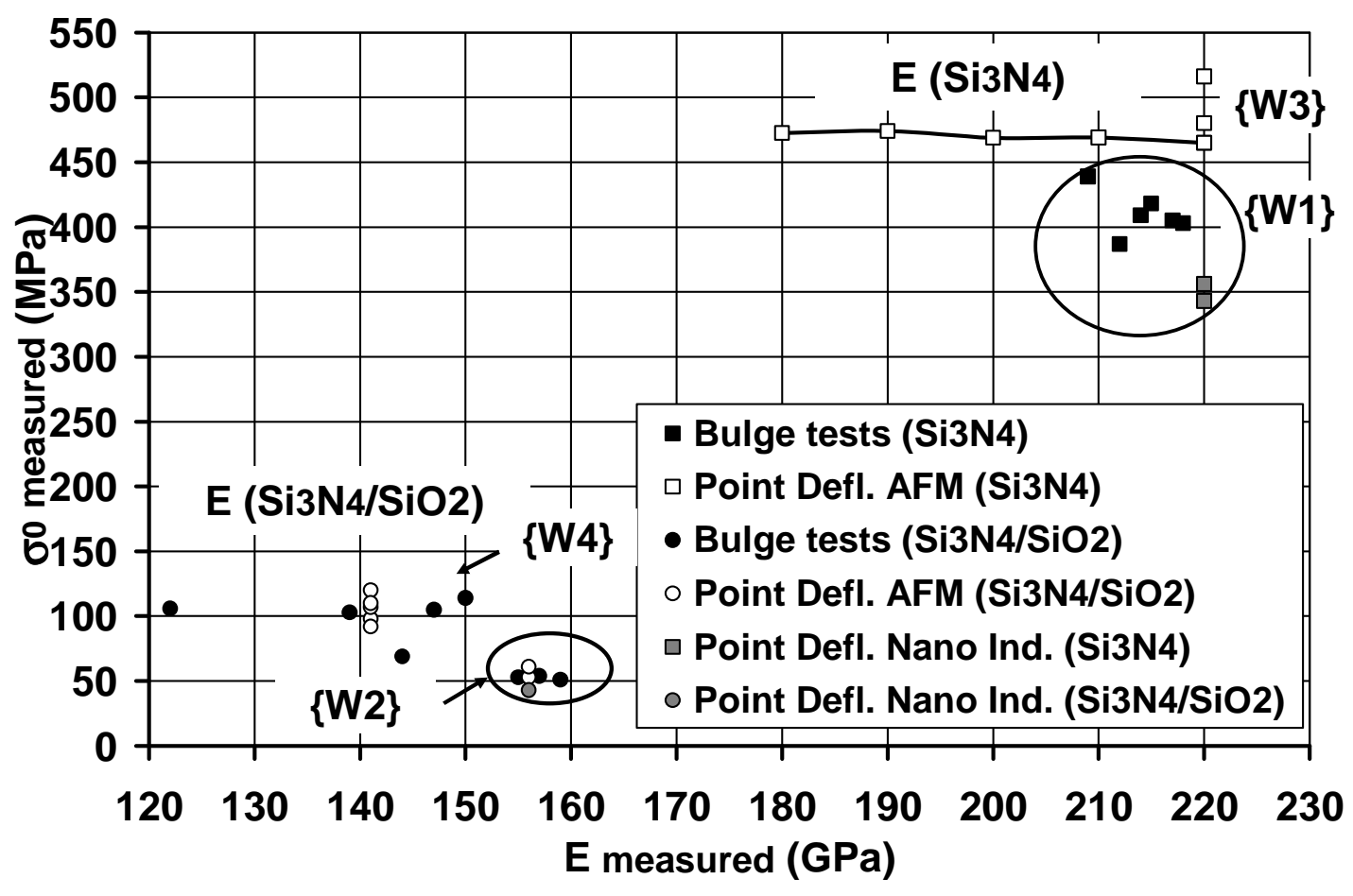

Fig .14 